\title{
Heat pump working fluid selection-economic and thermodynamic comparison of criteria and boundary conditions
}

\author{
Zühlsdorf, Benjamin; Jensen, Jonas Kjær; Elmegaard, Brian
}

Published in:

International Journal of Refrigeration

Link to article, DOI:

10.1016/j.ijrefrig.2018.11.034

Publication date:

2019

Document Version

Peer reviewed version

Link back to DTU Orbit

Citation (APA):

Zühlsdorf, B., Jensen, J. K., \& Elmegaard, B. (2019). Heat pump working fluid selection-economic and thermodynamic comparison of criteria and boundary conditions. International Journal of Refrigeration, 98, 500513. https://doi.org/10.1016/j.ijrefrig.2018.11.034

\section{General rights}

Copyright and moral rights for the publications made accessible in the public portal are retained by the authors and/or other copyright owners and it is a condition of accessing publications that users recognise and abide by the legal requirements associated with these rights.

- Users may download and print one copy of any publication from the public portal for the purpose of private study or research.

- You may not further distribute the material or use it for any profit-making activity or commercial gain

- You may freely distribute the URL identifying the publication in the public portal 


\title{
Heat pump working fluid selection - Economic and thermodynamic comparison of criteria and boundary conditions
}

\author{
Benjamin Zühlsdorf ${ }^{* 1}$, Jonas Kjær Jensen ${ }^{1}$, B. Elmegaard ${ }^{1}$ \\ ${ }^{1}$ Department of Mechanical Engineering, Technical University of Denmark, Nils Koppels Allé, Bygning 403, 2800 Kgs. Lyngby, \\ Denmark
}

\begin{abstract}
The study analyzes approaches for the selection of working fluids for the design of heat pump cycles based on numerical modeling. Different approaches for defining economically reasonable assumptions for the heat exchanger dimensioning were compared with respect to the identification of thermodynamically and economically promising working fluids. It was revealed that comparisons based on fixed heat exchanger investment do not exploit the performance of potentially high performing fluids. The approach of defining the pinch point temperature differences in the heat exchangers was found to provide results that were closest to the economic optimum, while being readily applicable in screening procedures. The method was demonstrated by two examples using excess heat from data centers for district heating supply. For the two cases, zeotropic mixtures were identified that could improve the thermodynamic performance by $30 \%$ to $35 \%$ while achieving a reduction of levelized cost of heat of $8 \%$ to $10 \%$.
\end{abstract}

\section{Highlights}

- Approaches for comparing pure and mixed working fluids were evaluated

- Comparison based on fixed investment may cause omission of high-performance fluids

- Comparison based on fixed pinch point temperature differences yields fairer results

- Using zeotropic mixtures can improve the thermodynamic performance significantly

- The performance increase can compensate the investment and improve economics

Keywords: Data center cooling, District heating, Heat pump design, Industrial heat pump, Refrigerant selection, Temperature glide matching, Zeotropic Mixture

\section{Introduction}

Heat pumps constitute a possibility for efficient electricity-based heat supply, and an increasing demand for high-performance equipment for these is obvious. The performance of a heat pump is limited by the temperatures of the heat source and the heat sink and the maximum achievable performance is described by the Lorenz cycle, (Lorenz, 1894). To what extent the maximum achievable performance can be exploited depends strongly on the working fluid, but the choice of working fluid may be limited by legislative regulations currently experiencing further restricting modifications. Velders et al. $(2015,2009)$ have shown the significant environmental impact of hydrofluorocarbons (HFCs) and the phase-down of most HFCs was adopted, (European Parliament, 2014; United Nations Environmental Programme, 2016). The regulations affect widely used refrigerants and increase the demand for sustainable and efficient solutions even more.

\footnotetext{
${ }^{*}$ Corresponding Author

Email addresses: bezuhls@mek.dtu.dk (B.Zühlsdorf); jkjje@mek.dtu.dk (J. K. Jensen); be@ mek.dtu.dk (B. Elmegaard)
} 
One approach to counteract the phase-down of HFCs is the exploration of novel working fluids. Domanski et al. (2014) analyzed the performance limits for conventional refrigeration applications that are obtainable under the assumption that the search space of fluid properties is continuous. McLinden et al. (2014) complemented the work and conducted a screening, in which compounds from comprehensive databases composed the potential working fluids. This procedure was not limited to available refrigerants and theoretically covered the entire range of feasible solutions, which let the authors present an exhaustive list of possible working fluids. The same authors showed in McLinden et al. (2017) that this list of suitable fluids was rather limited compared to the initial search space to which the screening methods were associated.

Another approach is to extend the application range of available and well known working fluids by blending them. Mixing fluids implies an alteration of the fluid properties. If the mixture is an azeotropic mixture, it behaves similarly to pure fluids and can potentially serve as a replacement. However, most mixtures are zeotropic and show a temperature glide during phase change. While this behavior decreases the possibilities of using zeotropic mixtures as replacements for conventional fluids it offers performance improvement potentials for applications in which the heat source and heat sink show a similar temperature profile as the working fluid during evaporation and condensation.

Radermacher and Hwang (2005) have shown that the utilization of zeotropic mixtures as working fluids enables choosing the fluid in order to obtain an improved match of the temperature profiles of the heat sink and source and the working fluid, which experiences a temperature glide during evaporation and condensation. Studies, such as (Högberg and Berntsson, 1994) and (McLinden and Radermacher, 1987), have described the benefits which are obtainable by selecting the working fluids among zeotropic mixtures with the aim of matching the temperature profiles with the heat source and heat sink.

Zühlsdorf et al. have shown in different studies, e.g. (Zühlsdorf et al., 2018a), (Zühlsdorf et al., 2018c), (Zühlsdorf et al., 2018d) and (Zühlsdorf et al., 2017), that an integration of heat pumps into given boundary conditions yields more efficient solutions, when the integration process comprises the heat pump design and a simultaneous screening of the working fluid among pure and mixed refrigerants. The studies have shown that the potential performance increase from utilizing zeotropic working fluid mixtures varies according to the boundary conditions and can reach possible increases of more than $40 \%$ (Zühlsdorf et al., 2018c), relative to the performance of pure fluids.

The screening of working fluids requires the establishment of performance indicators suitable for comparison purposes. This paper therefore discusses suitable indicators including the underlying assumptions and suggests a method for a working fluid selection, which ensures an optimal integration of the heat pump into given boundary conditions. The screening of working fluids comprises both pure and mixed working fluids and aims to support the initial design stage, rather than retrofitting studies.

The information included in the performance indicators and the underlying assumptions are dependent on each other and different approaches are presented in literature, which might be more or less suitable for different purposes. McLinden and Radermacher (1987) evaluated different approaches for comparing the performance of pure and mixed fluids. They showed that any comparison that is based on internal cycle temperatures, such as inlet, outlet or average evaporation or condensation temperatures, constitutes an insufficient basis for comparisons using the COP. They point out that this approach disregards that the solutions are able to operate between different boundary conditions in terms of source and sink temperatures, meaning that the same COP corresponds to different second law efficiencies. Such comparisons, as recently performed by e.g. Venzik et al. (2017), may only be considered as reasonable when the comparison seeks to find a fluid for an application with constant temperature reservoirs, or when second law efficiencies are used to compare the performances, because they only compare the cycle performance, while neglecting the integration into the boundary conditions. However, the main benefit of mixed working fluids does not lie within the internal cycle itself, but rather in a better integration into boundary conditions with temperature glides, meaning a more efficient heat transfer at smaller temperature differences to sink and source. 
McLinden et al. (2017), McLinden and Radermacher (1987) and Högberg and Berntsson (1994) suggest instead comparing the fluids based on a fixed ratio of the total UA-value in relation to either the supplied heat or cold $U A / \dot{Q}$. This corresponds to a fixed UA-value if a fixed heat load and a fixed value of the logarithmic mean temperature difference $\Delta T_{\mathrm{lm}}$ are assumed. This approach was also followed in further works to compare mixtures experimentally, (Mulroy et al., 1994), and by numerical simulations, (Domanski et al., 1994; Domanski and McLinden, 1990; McLinden et al., 2017). For the experimental analysis using the same equipment Domanski et al. (1994) recommend adjustment of the supplied heat flow rate by controlling the compressor volume flow rate to obtain a comparable ratio of $\mathrm{UA} / \dot{Q}$.

Another approach to evaluate the working fluids is fixing the minimum pinch point temperature differences in the heat exchangers. This approach was adopted in previous studies, (Zühlsdorf et al., 2017, 2018a, 2018c, 2018d), and it was found to be a suitable way of sizing the heat exchanger area while identifying fluids with a high thermodynamic performance. Other authors, e.g. (Bamigbetan et al., 2018, 2016; Besbes et al., 2014; Dai et al., 2014; Zoughaib, 2017), adopted the approach as well.

This paper performs a critical analysis of known approaches for comparison of working fluids with respect to their applicability for the evaluation of pure and mixed working fluids for high-performance heat pump cycles. The different approaches are discussed on a theoretical basis and by the example of the two case studies. Based on these findings, recommendations for suitable approaches for comparing different working fluids are derived and a screening procedure is suggested.

\section{Methods}

This chapter develops a general method for evaluating and comparing different pure and mixed working fluids for the basic cycle design of a heat pump cycle. The general thermodynamic cycle layouts, possible assumptions for the cycle design and accordingly meaningful performance indicators are introduced and analyzed. Furthermore, a screening procedure is suggested and recommendations for evaluating the screening results are given. The description of the methods introduces different options which might be more or less suitable depending on the application. Two case studies for the demonstration of the method are subsequently introduced before the different approaches of dimensioning the heat exchangers and designing the cycle are discussed theoretically and on a basis of the introduced case studies.

\subsection{Thermodynamic cycles}

This paper aims to assess approaches for comparing the performance of heat pumps with different working fluids, rather than different cycle layouts. The focus lies therefore on simple cycle layouts, as presented in Figure 1 and Figure 2.

Figure 1 shows the layout and a temperature-heat-diagram of a standard cycle with the minimum number of required components. The working fluid receives heat from the heat source while it is evaporated $(6 \rightarrow 7)$ and superheated $(7 \rightarrow 1)$ before being compressed $(1 \rightarrow 2)$ to reject heat at high pressure. The heat rejection $(2 \rightarrow 5)$ consists of desuperheating $(2 \rightarrow 3)$, condensation $(3 \rightarrow 4)$ and subcooling $(4 \rightarrow 5)$. The definition of these processes is distinct in the two-phase region and becomes smooth in the supercritical region. The working fluid is subsequently throttled to the low pressure $(5 \rightarrow 6)$. Figure 2 shows the layout of a cycle with an internal heat exchanger (IHX), which utilizes the potential of further subcooling $(5 \rightarrow 6)$ to superheat the working fluid $(8 \rightarrow 1)$. The internal heat exchanger implies the possibility to realize the required superheating and potentially some part of the evaporation process.

While the standard cycle is expected to show promising performances for applications with a small difference between the source and sink inlet temperature, the IHX-cycle is expected to show better performances for increasing differences. McLinden et al. (2017) suggest additionally considering a two-stage compression cycle with an open intercooler, which also aims to lower irreversibilities caused by the expansion processes and to improve the compression by introducing a two-stage compression. This cycle is however not 
considered in this study, since it requires an additional compression stage and since a possibly negative effect on the performance for zeotropic mixtures was expected. This analysis is limited to single stage cycles without devices for recovery of expansion work, but can be extended to other cycles accordingly.
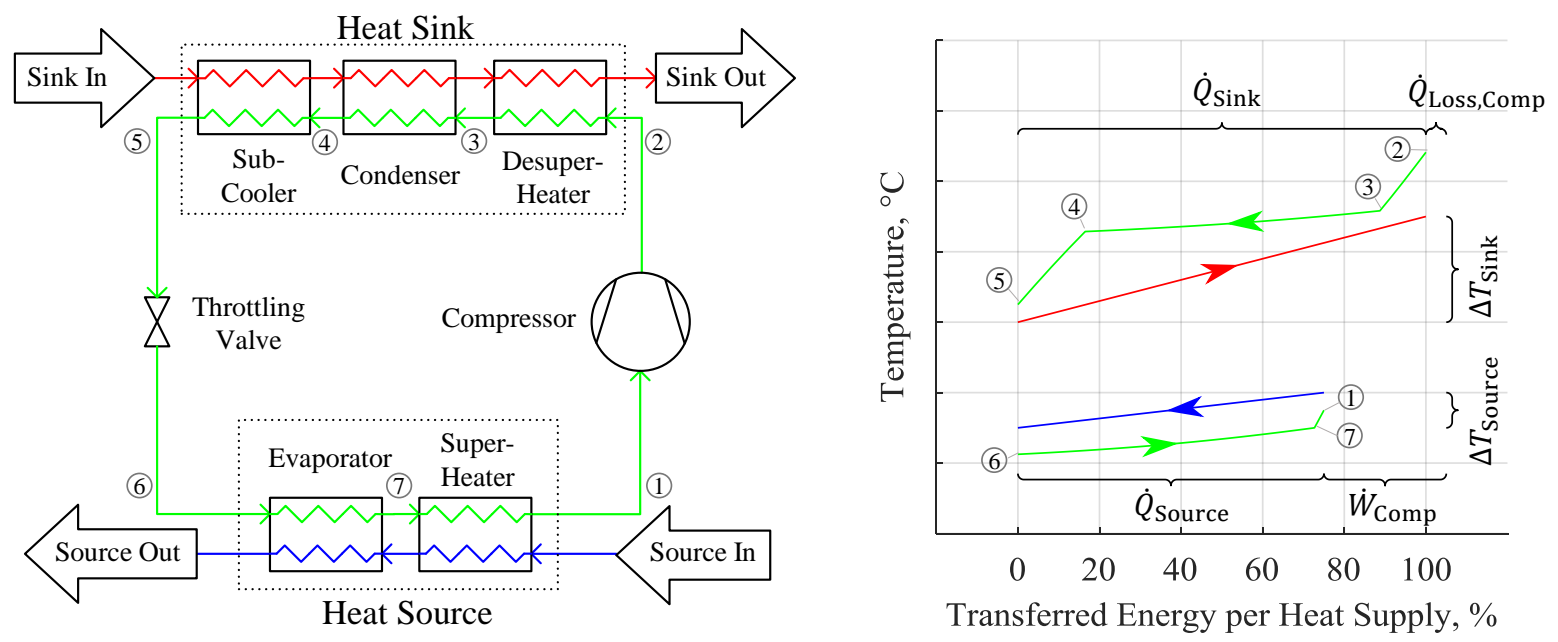

Figure 1: Flow sheet (left) and Temperature-Heat-Diagram (right) of the standard cycle
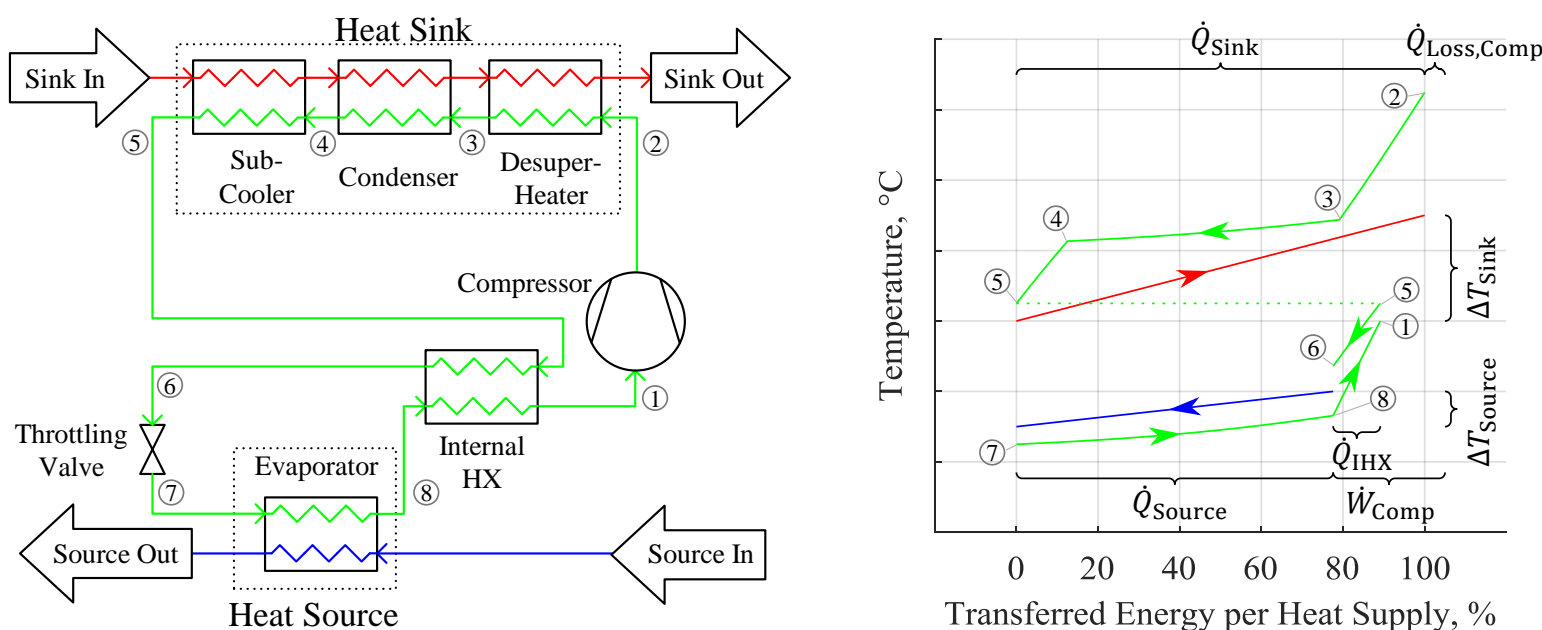

Figure 2: Flow sheet (left) and Temperature-Heat-Diagram (right) of the IHX-cycle

The numerical cycle models were based on energy and mass balances. The compressor was modelled with an isentropic efficiency and potentially considering heat losses. The pressure levels were defined by minimum or average temperature differences between the streams, or alternatively by giving sufficient information about the heat exchangers as discussed in the following sections. The models were implemented in Matlab (The MathWorks Inc., 2018) using fluid properties from Refprop 9.1 (Lemmon et al., 2013). The numerical models are documented in detail in (Zühlsdorf et al., 2018b) and are publically available.

\subsection{Performance indicators}

The method focusses on the design and comparison of heat pump cycles. In order to establish a basis for rational comparison, suitable evaluation criteria and accordingly appropriate assumptions were identified. 


\subsubsection{Thermodynamic performance}

The thermodynamic performance is measured by the coefficient of performance COP, which describes the ratio between supplied heat $\dot{Q}_{\text {Sink }}$ and consumed power $\dot{W}_{\text {Comp. }}$

$$
\mathrm{COP}=\frac{\dot{Q}_{\text {Sink }}}{\dot{W}_{\text {Comp }}}
$$

The COP is commonly used and the focus of the most studies. A meaningful interpretation of the COP does nonetheless require that the inlet and outlet temperatures of the heat source and heat sink are the same in all cases. If these are not fixed during the comparisons, second law efficiencies are a more appropriate choice as they account for the boundary conditions (Jensen et al., 2018; Van de Bor and Infante Ferreira, 2013).

The Lorenz efficiency $\eta_{\text {Lor }}$ is defined as the COP in relation to the maximum obtainable COP $\mathrm{Lor}_{\text {of a }}$ Lorenz cycle.

$$
\eta_{\text {Lor }}=\frac{\mathrm{COP}}{\mathrm{COP}_{\text {Lor }}}
$$

(Lorenz, 1894) defines the $\mathrm{COP}_{\mathrm{Lor}}$ analogously to the Carnot $\mathrm{COP}_{\mathrm{Car}}$ while accounting for the temperature glides, by using the thermodynamic average temperatures of the heat source $\bar{T}_{\text {Source }}$ and sink $\bar{T}_{\text {Sink }}$. The thermodynamic average temperatures were defined as the entropic mean temperature $\bar{T}=\Delta h / \Delta s$ and may be calculated as the logarithmic mean temperature $\bar{T}_{\mathrm{lm}}=\left(T_{1}-T_{2}\right) / \ln \left(T_{1} / T_{2}\right)$ for streams of constant heat capacity, (Bejan et al., 1996, chap. 3.5). Equation 3 introduces the Carnot cycle COP based on the largest lift between the source and sink.

$$
\mathrm{COP}_{\text {Car }}=\frac{T_{\text {Sink,out }}}{T_{\text {Sink,out }}-T_{\text {Source,out }}}
$$

Equation 4 presents the Lorenz cycle COP.

$$
\operatorname{COP}_{\text {Lor }}=\frac{\bar{T}_{\text {Sink }}}{\bar{T}_{\text {Sink }}-\bar{T}_{\text {Source }}}
$$

The thermodynamic cycle yields additional parameters, which can indicate the investment cost and the technical feasibility. The volumetric heating capacity VHC is defined by the ratio of the heat supplied per unit of compressed volume flow rate and gives therefore an indication of the compressor size, which can e.g. be used to estimate the investment cost of positive displacement compressors.

$$
\mathrm{VHC}=\frac{h_{2}-h_{5}}{v_{1}}
$$

Further indication of the technical feasibility can be derived from parameters such as the pressure levels, the pressure ratio and compressor suction and discharge temperatures.

\subsubsection{Economic performance}

The economic performance can be described by different parameters considering both the annual cash flows and one-time investments.

The one-time investments can be summarized as the total capital investment cost TCI as an absolute value or as a specific value in relation to the supplied heat capacity $\mathrm{TCI}_{\text {spec }}=\mathrm{TCI} / \dot{Q}_{\text {Sink. }}$. The TCI of the heat pump describes the cost of the entire investment, including the cost for the equipment, the assembly, the installation and start-up and other expenses that may be related to the investment. The TCI can be simplified determined as a fixed multiple $f_{\mathrm{TCI}}$ of the purchased equipment cost PEC of the main components. The factor $f_{\mathrm{TCI}}$ accounts for the remaining expenses and often is an experience-based value, that can vary e.g. between 4.16 for an extension of an existing plant to 6.32 for the erection of a new system, (Bejan et al., 1996, chap. 7). Examples 
of the calculation of heat pump investment costs are e.g. published by (Jensen et al., 2015; Nielsen et al., 2018; Ommen et al., 2015; Zühlsdorf et al., 2018c).

$$
\mathrm{TCI}=f_{\mathrm{TCI}} \mathrm{PEC}
$$

The purchased equipment cost PEC consists of the acquisition cost of the main components, which are for the case of a heat pump the compressor and the heat exchangers. The component costs can be obtained from suppliers or by means of suitable cost functions as suggested by e.g. (Bejan et al., 1996).

The operational cost can be characterized by annual cash flows for incomes and expenses. In the case of a heat pump, the expenses consist of the fuel cost for the consumed electricity $\mathrm{CF}_{\mathrm{el}}$. The income $\mathrm{CF}_{\text {Supply }}$ is achieved by the supply of heat that is transferred to the heat sink. If the heat pump replaces e.g. a natural gas boiler, the income is considered as the savings that are obtained by not operating the boiler. The cash flow associated to the heat source $\mathrm{CF}_{\text {Source }}$ can be negative when representing an expense in case the heat is to be paid or positive when representing an additional income, e.g. from offering a cooling service.

The comparison of annual cash flows and one-time expenses requires the calculation of present time values of future expenses, which was done by the capital recovery factor CRF assuming an effective interest rate $i_{\text {eff }}$ and a lifetime of the plant of $n$ years, (Bejan et al., 1996, chap. 7).

$$
\mathrm{CRF}=\frac{\left(1+i_{\text {eff }}\right)^{n}-1}{i_{\text {eff }}\left(1+i_{\text {eff }}\right)^{n}}
$$

Using the CRF allows to define the net present value NPV describing the overall value of the investment at the time of the investment by accumulating the TCI and the annual cash flows as their present value. In case that one-time savings are obtained by replacing existing equipment, these might be considered in the TCI.

$$
\mathrm{NPV}=-\mathrm{TCI}+\frac{\mathrm{CF}_{\text {Supply }}-\mathrm{CF}_{\mathrm{el}}+\mathrm{CF}_{\text {Source }}}{\mathrm{CRF}}
$$

The simple payback time PBT determines how many years are required to compensate the initial investment and may be used as an additional basis for assessing the potential investment.

$$
\mathrm{PBT}=\frac{\mathrm{TCI}}{\mathrm{CF}_{\text {Supply }}-\mathrm{CF}_{\mathrm{el}}+\mathrm{CF}_{\text {Source }}}
$$

Another indicator for comparing the technology to its alternatives is the specific cost of heat $c_{\mathrm{h}}$. This cost relates the annual operating cost $\mathrm{CF}_{\mathrm{el}}$, the annual operating cost or income $\mathrm{CF}_{\text {Source, }}$ as well as the annual equivalent of the investment cost TCI.CRF, to the amount of supplied heat $\dot{Q}_{\text {Sink }}$ per year during OH operating hours.

$$
c_{\mathrm{h}}=\frac{\mathrm{CF}_{\mathrm{el}}-\mathrm{CF}_{\text {Source }}+\mathrm{TCI} \cdot \mathrm{CRF}}{\dot{Q}_{\text {Sink }} \cdot \mathrm{OH}}
$$

The economic performance is strongly dependent on the economic boundary conditions of the specific case and therefore on input parameters implying large variations. This causes economic feasibility calculations to include significant uncertainty. If the above-mentioned boundary conditions are known, e.g. for specific case studies, an economic analysis provides reliable information for evaluating a potential investment.

It may furthermore be noted that the methods for calculating TCI are dependent on experience-based factors and component-based cost functions that have to be validated with calculations that are more detailed.

\subsubsection{Additional secondary performance indicators}

The environmental performance of working fluids is of special interest when comparing natural and synthetic working fluids. Besides the working fluid properties, such as the ozone depletion potential ODP or the global warming potential GWP, additional analyses considering the entire lifecycle of the refrigerant and the unit may be conducted. Lee et al. (2016) suggests conducting a lifecycle climate performance as described 
by (Guideline for Life Cycle Climate Performance, 2016) to estimate the complete environmental impact associated with the refrigerants.

The flammability of refrigerants constitutes an additional aspect that is considered in working fluid selection. Different studies, such as (Vonsild, 2017), have however presented approaches to handle flammability. The flammability of mixtures can be calculated as described by Crowl and Louvar (2001).

\subsection{Boundary conditions for working fluid evaluation}

The focus of the analysis is working fluids for a heat pump application to be used in a specific application. The boundary conditions in terms of heat source inlet and outlet temperatures, $T_{\text {Source,in }}$ and $T_{\text {Source,out, }}$ as well as the heat sink inlet and outlet temperatures, $T_{\text {Sink,in }}$ and $T_{\text {Sink,out }}$, are assumed to be defined by the application, e.g. by heating and cooling requirements. Additionally one parameter defining the load of the cycle was defined. This could be either the heating $\dot{Q}_{\text {Sink }}$ or cooling requirements $\dot{Q}_{\text {Source. }}$

\subsubsection{Thermodynamic cycle}

Designing the thermodynamic cycle requires fixing the pressure levels during heat absorption and rejection. Considering the fixed heat source and sink temperatures, the choice of the pressure levels is linked to the temperature differences in the heat exchangers and thereby to the required heat exchanger area. Different approaches were presented to fix this design problem and the optimal choice of the approach is determined by the application. As the presented screening procedure aims to identify fluids with a high thermodynamic performance, we recommend to fix the minimum pinch point temperature differences in the heat exchangers. The different approaches are however discussed in more detail in chapter 2.6.

\subsubsection{Component dimensioning}

A thermodynamic comparison provides a good indication of the general performance of working fluid candidates, especially for cases in which the thermodynamic performance is dominating the economic performance or in combination with indicators of the investment cost, such as the volumetric heating capacity or the UA-values. A comparison based on the thermodynamic performance is furthermore relatively robust with respect to the modelling assumptions.

An economic assessment can provide an additional view on the general profitability of the solutions. A detailed economic analysis requires anyhow a detailed design of the components and the determination of the component costs. This procedure can be exercised with a range of levels of detail. A very detailed design procedure can provide investment cost with increased accuracy, while more simplified approaches are able to provide cost estimations suitable for comparison purposes with a reasonable effort, (Zühlsdorf et al., 2017, 2018c). Using simplified methods for the economic assessment appears to be of sufficient accuracy when considering that the economic boundary conditions, such as plant lifetime, interest rates or fuel cost, are anyhow case specific and subject to large uncertainties.

Section 2.2.2 presented an approach to evaluate the economic performance based on the component cost of the main components. (Bejan et al., 1996) suggested using the heat exchange area to correlate the investment cost for the heat exchanger equipment and the volume flow rate for the compressor size. The volume flow rate of the compressor is directly obtainable from the thermodynamic calculations, while the determination of the heat exchanger size requires an estimation of the heat transfer coefficients.

The design of the heat exchangers implies fixing a tradeoff among the pressure drop and the heat transfer coefficients. This relation can be optimized with respect to the economic performance, while such an optimization appears to be too comprehensive to be included in the evaluation of several hundreds of fluids. (Mancini et al., 2018) presents an approach for deriving suitable design guidelines for plate heat exchangers and furthermore suggests a method for this. Alternatively, the heat exchangers might be designed by estimating heat transfer coefficients. A conservative estimation of the heat transfer coefficients ensures that the assumed values are obtainable under acceptance of reasonable pressure drops. 


\subsection{Screening Process}

Different studies, e.g. (McLinden et al., 2017), (Frutiger et al., 2018) and (Cignitti, 2018), have performed comprehensive screenings for specific applications. McLinden et al. (2017) summarizes the works on working fluid screenings among extensive databases and concludes the options for working fluid options to be limited. The provided list of fluids that are consistent with current legislation includes the common natural refrigerants and hydrofluoroolefins (HFOs).

In order to evaluate the performance of possible working fluids, we suggest defining a list of fluids that are used to generate binary mixtures. The list of fluids can e.g. be the pure fluids mentioned in (McLinden et al., 2017) but it should only include fluids that are generally acceptable for the application.

Previous studies, e.g. (Zühlsdorf et al., 2018a) and (Cignitti, 2018), did not reveal clear optima for key thermodynamic parameters, such as the critical temperature or pressure. We therefore recommend compiling the list of considered fluids to cover a wide range of these parameters. The fluids should furthermore be miscible for a wide range of compositions.

Table 1: List of fluids considered in the screening with characteristic properties (ASHRAE, 2016; Bell et al., 2014; Dansk Standard, 2016; Fukuda et al., 2014; Myhre et al., 2013)

\begin{tabular}{|c|c|c|c|c|c|c|c|c|c|}
\hline No. & Name of Fluid & Ref. No.: & Type & $\begin{array}{c}\text { ODP } \\
-\end{array}$ & $\begin{array}{c}\text { GWP } \\
-\end{array}$ & $\begin{array}{c}\text { Normal } \\
\text { Boiling } \\
\text { Point, }{ }^{\circ} \mathrm{C}\end{array}$ & $\begin{array}{l}\text { Crit. } \\
\text { Temp. } \\
{ }^{\circ} \mathrm{C}\end{array}$ & $\begin{array}{c}\text { Crit. } \\
\text { Pressure, } \\
\text { bar }\end{array}$ & $\begin{array}{l}\text { Safety } \\
\text { Class }\end{array}$ \\
\hline 1 & Methane & $\mathrm{R}-50$ & $\mathrm{HC}$ & 0 & 25 & -161.5 & -82.6 & 46.0 & A3 \\
\hline 2 & Ethylene & R-1150 & $\mathrm{HO}$ & 0 & 4 & -103.8 & 9.2 & 50.4 & A3 \\
\hline 3 & Ethane & $\mathrm{R}-170$ & $\mathrm{HC}$ & 0 & 6 & -88.6 & 32.2 & 48.7 & A3 \\
\hline 4 & Carbon dioxide & $\mathrm{R}-744$ & & 0 & 1 & - & 31.0 & 73.8 & A1 \\
\hline 5 & Propylene & $\mathrm{R}-1270$ & $\mathrm{HO}$ & 0 & 2 & -47.6 & 91.1 & 46.7 & A3 \\
\hline 6 & Propane & R-290 & $\mathrm{HC}$ & 0 & 3 & -42.0 & 96.7 & 42.5 & A3 \\
\hline 7 & Dimethyl ether (DME) & R-E170 & Ether & 0 & 1 & -24.0 & 127.3 & 53.4 & A3 \\
\hline 8 & Iso-Butane & R-600a & $\mathrm{HC}$ & 0 & 3 & -11.7 & 134.7 & 36.3 & A3 \\
\hline 9 & n-Butane & $R-600$ & $\mathrm{HC}$ & 0 & 4 & -0.5 & 152.0 & 38.0 & $\mathrm{~A} 3$ \\
\hline 10 & Iso-Pentane & R-601a & $\mathrm{HC}$ & 0 & 4 & 27.8 & 187.3 & 33.8 & A3 \\
\hline 11 & Ethyl ether (DEE) & R-610 & Ether & 0 & 5 & 34.6 & 193.7 & 36.4 & A3 \\
\hline 12 & Pentane & $\mathrm{R}-601$ & $\mathrm{HC}$ & 0 & 5 & 36.1 & 196.6 & 33.7 & A3 \\
\hline 13 & n-Hexane & & $\mathrm{HC}$ & & & 68.7 & 234.5 & 30.3 & \\
\hline 14 & Heptane & & $\mathrm{HC}$ & & & 98.4 & 267.0 & 27.4 & \\
\hline 15 & & R-1234yf & $\mathrm{HFO}$ & 0 & $<1$ & -26.0 & 94.7 & 33.8 & A2L \\
\hline 16 & & R-1234ze(E) & $\mathrm{HFO}$ & 0 & $<1$ & -19.0 & 109.4 & 36.4 & A2L \\
\hline 17 & & R-1234ze(Z) & $\mathrm{HFO}$ & 0 & $<1$ & 9.8 & 150.1 & 35.3 & $\mathrm{~A} 2 \mathrm{~L}^{\#}$ \\
\hline 18 & & $\mathrm{R}-1233 \mathrm{zd}(\mathrm{E})$ & $\mathrm{HCFO}$ & $\sim 0$ & 4.5 & 17.9 & 166.5 & 36.2 & A1 \\
\hline
\end{tabular}

${ }^{\#}$ Expected values according to (Fukuda et al., 2014)

Table 1 shows a possible list of pure fluids to be considered in the screening process. The list contains 14 natural refrigerants and 4 HFOs. It might be adjusted with respect to the specific application. Ammonia (R717) and water (R-718) were omitted from the list due to limited miscibility with many of the other refrigerants. Comparing the results from screenings based on this list to the results that were obtained by screenings considering a larger number of fluids (Cignitti, 2018) suggests that no further significant improvements are to be expected. Composing the list of fluids by commonly known fluids or fluids with similar behavior, e.g. heptane and hexane, might enhance the practical applicability, since similar equipment for sealing and lubrication might be useable. Mixtures might additionally be blended with the purpose of obtaining a specific desired effect, by blending $\mathrm{CO}_{2}$ with hydrocarbons to decrease the gas cooler pressure of $\mathrm{CO}_{2}$ and the flammability of hydrocarbons, (Kim et al., 2008; Tobaly et al., 2018).

The thermodynamic models used medium properties provided by the software Refprop 9.1 (Lemmon et al., 2013), which is considered as the current state of the art for binary mixtures (Bell and Lemmon, 2016). 
Refprop 9.1 contained medium properties that were mostly based on experimental data, in case experimental data of sufficient quality was available. For the binary mixtures, for which the available experimental data was insufficient, the binary interaction parameters were estimated based on (Lemmon and McLinden, 2001). This estimation was subject to the uncertainties, which resulted from the molecular structure of the components. The estimation was found to provide sufficient accuracy for some combinations, while specific fluids were showing larger uncertainties (Mondejar and Haglind, 2018). As the estimation was expected to provide sufficient accuracy for most of the fluids, we recommend not to exclude mixtures with estimated interaction parameters on beforehand, but to conduct an uncertainty analysis as part of the screening evaluation in case such mixtures indicate promising performance. If experimental data becomes available, the mixture could be re-evaluated using updated interaction parameters or an uncertainty analysis as described by (Frutiger et al., 2018, 2016) could be conducted.

In order to perform a working fluid screening, we suggest evaluating the above specified models for all possible binary combinations at equidistant composition steps, of e.g. $10 \%$. The screening results consist of a cycle simulation for each mixture and can be analyzed, sorted and filtered with respect to the presented thermodynamic, economic and further secondary performance indicators.

\subsection{Application to case studies}

In order to demonstrate and discuss the capabilities of the suggested method, the screening procedure was applied to two case studies. Table 2 summarizes the thermodynamic and economic boundary conditions of the two case studies. The case studies focus on the integration of a heat pump to utilize the excess heat from data centers for supplying district heating. The temperatures for the cooling stream for the data centers vary according to the technologies, (ASHRAE Technical Committee, 2016). Both cases assumed a temperature of $25^{\circ} \mathrm{C}$ at the data center inlet. Case I assumed an outlet temperature of $50{ }^{\circ} \mathrm{C}$, while a lower allowable temperature increase in the server rooms was assumed for case II, resulting in an outlet temperature of $40{ }^{\circ} \mathrm{C}$. The required cooling load was assumed to be $500 \mathrm{~kW}$ in both cases. The temperatures of the district heating system were assumed to be $50{ }^{\circ} \mathrm{C}$ in the return and $75{ }^{\circ} \mathrm{C}$ in the forward line. The heat flow rate supplied to the district heating network was determined by the cooling demand and the heat pump performance.

It may be noted that the cases were chosen to be exemplifying cases with a certain relevance for given applications. The demonstrated procedure instead is independent of the cases and the presented results may give indications for other applications with similar boundary conditions.

Table 2: Thermodynamic and economic boundary conditions for case studies and modelling assumptions for the heat pump design

\begin{tabular}{|c|c|c|}
\hline & Case I & Case II \\
\hline \multicolumn{3}{|l|}{ Boundary conditions: } \\
\hline Heat source $T_{\text {Source,in }} \rightarrow T_{\text {Source,out: }}$ & $50^{\circ} \mathrm{C} \rightarrow 25^{\circ} \mathrm{C}$ & $40^{\circ} \mathrm{C} \rightarrow 25^{\circ} \mathrm{C}$ \\
\hline Heat $\operatorname{sink} T_{\text {Sink,in }} \rightarrow T_{\text {Sink,out: }}$ & \multicolumn{2}{|c|}{$50^{\circ} \mathrm{C} \rightarrow 75^{\circ} \mathrm{C}$} \\
\hline Supplied cooling $\dot{Q}_{\text {Source }}:$ & \multicolumn{2}{|c|}{$500 \mathrm{~kW}$} \\
\hline Specific electricity cost $c_{\mathrm{el}}$ : & \multicolumn{2}{|c|}{$120 € / \mathrm{MWh}$} \\
\hline Specific income per supplied heat $c_{\text {Sink }}$ : & \multicolumn{2}{|c|}{$40 € / \mathrm{MWh}$} \\
\hline Specific cash flow per supplied cooling $c_{\text {Source }}$ : & \multicolumn{2}{|c|}{$0 € / \mathrm{MWh}$} \\
\hline Operating hours per year: & \multicolumn{2}{|c|}{$8000 \mathrm{~h} /$ year } \\
\hline Lifetime $n$ : & \multicolumn{2}{|c|}{20 years } \\
\hline Effective interest rate $i_{\text {eff: }}$ & \multicolumn{2}{|c|}{$5 \%$} \\
\hline \multicolumn{3}{|l|}{ Heat pump modelling assumptions: } \\
\hline Analyzed cycle: & Standard cycle & IHX cycle \\
\hline Isentropic compressor efficiency: & \multicolumn{2}{|l|}{$75 \%$} \\
\hline Motor efficiency: & \multicolumn{2}{|c|}{$95 \%$} \\
\hline$\Delta T_{\text {Pinch: }}$ & \multicolumn{2}{|c|}{$3 \mathrm{~K}$} \\
\hline Subcooling: & \multicolumn{2}{|c|}{$T_{5}=T_{\text {Sink,in }}+\Delta T_{\text {Pinch }}$} \\
\hline Evaporator outlet: & Superheated by $5 \mathrm{~K}$ & Saturated \\
\hline
\end{tabular}


The income for the investment consists of the district heating supply, which is assumed to be sold at $40 € / \mathrm{MWh}$, while the electricity is bought at $120 € / \mathrm{MWh}$. The economic boundary conditions constitute a representative scenario and are aligned to Danish conditions (Energistyrelsen, 2017; Zühlsdorf et al., 2018d). The application offers an additional income by replacing the existing cooling facilities but since these costs are highly uncertain, they were omitted from the economical assessment.

Table 2 shows the assumptions for the heat pump cycle design. The heat source inlet temperature of Case I was close to the heat sink inlet temperature and accordingly the standard cycle was chosen. Case II has a temperature difference of $10 \mathrm{~K}$ between the source and sink inlet temperature which increased the potential for the IHX-cycle instead.

Table 3 suggests a set of heat transfer coefficients to be used for an estimation of the heat transfer area and accordingly the investment costs. The values were adopted from (Zühlsdorf et al., 2018c) and were chosen to represent an approximate relation between liquid, gas and two-phase flow and to represent feasible solutions that are realizable for each fluid with an acceptable pressure drop. The values that were optimal for each solution were subject to further more detailed optimizations which were conducted for a limited set of fluids at a later design stage.

Table 3: Assumed heat transfer coefficients for simplified dimensioning of heat exchangers, (Zühlsdorf et al., 2018c)

\begin{tabular}{lcc}
\hline \multirow{2}{*}{ Flow condition } & \multicolumn{2}{c}{ Heat transfer coefficient, } \\
& Pure Fluid & Mixture \\
\hline Evaporation & 3,000 & 2,250 \\
Condensation & 2,400 & 1,800 \\
Liquid & \multicolumn{2}{c}{1,500} \\
Gaseous & \multicolumn{2}{c}{1,200} \\
\hline
\end{tabular}

The volumetric efficiency of the compressor was assumed to be $90 \%$. The cost functions for the estimation of the purchased equipment costs were adopted from (Zühlsdorf et al., 2017). No maintenance cost were assumed. The relation between equipment cost and total investment was $f_{\mathrm{TCI}}=4$, corresponding to experiences from the construction of a test rig and communication with potential suppliers.

\subsection{Analysis of the approaches for heat exchanger dimensioning}

The design of heat pump cycles as presented in Figure 1 and Figure 2 for given sink and source temperature profiles implies the tradeoff of fixing the temperature differences in the heat exchangers to either yield an improved performance and higher revenues during operation or a decreased performance at reduced investment cost. Larger temperature differences in the heat exchangers reduce the required heat exchanger size but also enlarge the differences between evaporation and condensation temperature and thereby reduce the COP.

Different approaches were introduced and are analyzed in this chapter. In the first section, the problem is analyzed theoretically on the basis of theoretical ideal cycles while the second section analyses the different approaches for the two introduced case studies.

\subsubsection{Theoretical analysis}

The transferred heat $\dot{Q}$ and the temperature difference $\Delta T$ of the involved streams are directly related by the heat conductance UA. The heat conductance is defined as the product of the heat transmission coefficient $U$ and the heat exchange area $A$ (Bejan et al., 1996).

$$
\dot{Q}=U A \Delta T_{\operatorname{lm}}=\mathrm{UA} \frac{\Delta T_{\text {in }}-\Delta T_{\text {out }}}{\ln \left(\Delta T_{\text {in }} / \Delta T_{\text {out }}\right)}
$$


Alefeld (1987) describes the limitation of an internal cycle that operates independently of the heat source and sink between the thermodynamic average temperatures of the evaporator $\bar{T}_{\text {Evap }}$ and the condenser $\bar{T}_{\text {Cond. }}$. These temperatures define the maximum COP of the internal cycle $\mathrm{COP}_{\text {Int,max }}$ under the assumption of isentropic compression and expansion. Ideally this would reach the COP of the Lorenz cycle for the source and sink.

$$
\operatorname{COP}_{\text {Int } \text { max }}=\bar{T}_{\text {Cond }} /\left(\bar{T}_{\text {Cond }}-\bar{T}_{\text {Evap }}\right)
$$

Figure 3 shows a temperature-heat-diagram of two heat pump cycles using an ideal pure fluid and an ideal mixed fluid for an application with temperature glides on both the source and the sink side. For both cycles superheat and desuperheat were neglected and the pure fluid rejects and receives heat without changing temperature, while the mixture shows a perfect match with the temperature profile of sink and source during heat transfer. The term "ideal" refers in this scenario to the abstraction of the fluids to show a linear temperature behavior, yielding an ideal performance for matching source and sink glides, rather than it refers to the optimum efficiency that might be obtained with any pure or fluid for the presented scenario. The diagram includes all temperatures that are relevant in the context of the heat exchanger areas as well as for the maximum achievable performance.

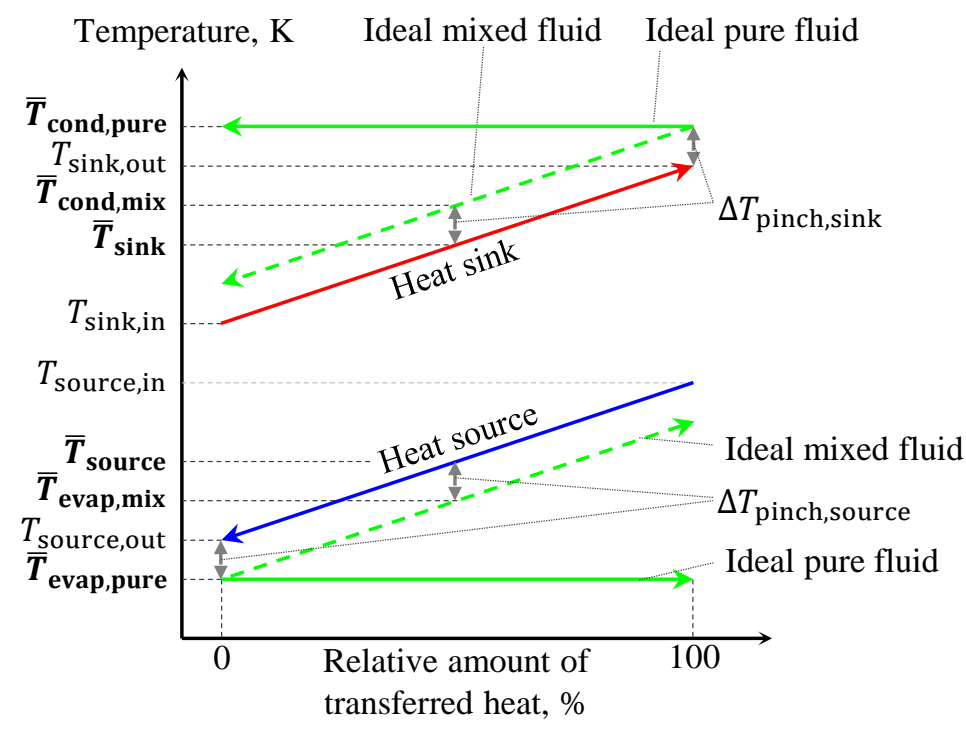

Figure 3: Temperature-heat-diagram of a simplified heat pump cycle operating with an ideal pure fluid and an ideal mixed fluid

Using these theoretical cycles, the dependencies of the overall UA-values and the minimum pinch point temperature differences on the performance of the two cycles were studied.

\subsubsection{Analysis based on case studies}

In order to analyze the different approaches more specifically, they were evaluated for a set of promising fluids for the presented case studies. The most promising were evaluated for three approaches. The cycle was designed by

a) fixing the minimum pinch point temperature differences,

b) fixing the overall investment associated with the heat exchangers to the value obtained for ammonia by approach a), and

c) by optimizing the heat exchanger area of the heat sink and heat source heat exchangers with respect to the net present value. 
During option c), a minimum temperature difference in the heat exchangers of $1 \mathrm{~K}$ was respected. The performances were compared in terms of COP and NPV. The analysis was conducted for the presented economic boundary conditions and repeated for the same boundary conditions with an assumed lifetime of $n=10$ years.

\section{Results}

This chapter presents the screening results for the two case studies, including both the thermodynamic and economic performance of the working fluids. Subsequently, the approaches for evaluating the working fluids are analyzed in a theoretical approach, before being compared based on the presented case studies.

\subsection{Screening results}

Case I: $T_{\text {Source }} 50^{\circ} \mathrm{C} \rightarrow 25^{\circ} \mathrm{C} ; T_{\text {sink }} \underline{50{ }^{\circ} \mathrm{C} \rightarrow 75^{\circ} \mathrm{C}}$

Figure 4 shows the COP (left) and the specific cost of heat $c_{\mathrm{h}}$ (right) for all possible fluids for case I. The most promising fluids are colored, while the remaining fluids are included in gray to visualize the entire solution space. The diagrams show that the pure fluids reach COPs of up to 4.5-4.6 and levelized specific heat regeneration cost as low as $31 € / M W h$ of supplied heat. Some of the mixtures show quite distinct differences in performance for limited variations of composition. Table 4 summarizes further performance indicators for the pure and mixed fluids that showed the lowest cost of heat. As ammonia constitutes a promising fluid with limited miscibility with the other considered fluids over a wide range, it was included as a pure fluid but not as a possible mixture component. It reaches a similar COP as the best fluids but a decreased $c_{\mathrm{h}}$ of $30.1 € / \mathrm{MWh}$. The COPs of the mixed fluids reach values as high as 6.7 and the cost of heat decreases to $27 € / \mathrm{MWh}$.

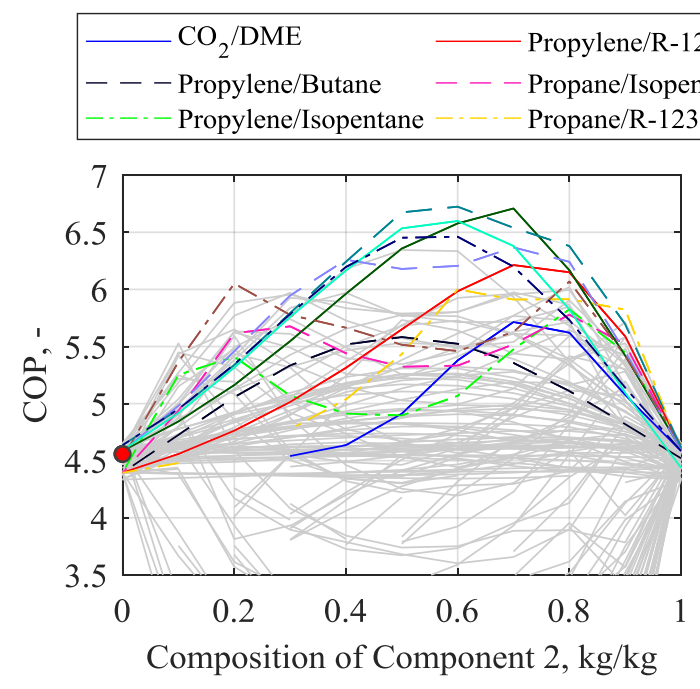

Figure 4: COP (left) and the specific cost of heat (right) over the composition of component 2 with most promising fluid indicated by colors for case I

Ammonia was the pure fluid with the best economic performance, while the mixture of $30 \%$ propylene and $70 \% \mathrm{R}-1234 \mathrm{ze}(\mathrm{Z})$ was the mixture with the best economic performance. The cost of supplied heat was $30.1 € / \mathrm{MWh}$ for ammonia and $26.7 € / \mathrm{MWh}$ for the mixture, while the COP was 4.6 and 6.2, respectively. This corresponds to an improvement of $11 \%$ in economic performance and $36 \%$ in thermodynamic performance. The NPV of the mixture is $25 \%$ higher than for ammonia, indicating that the increased thermodynamic performance is able to cover a twice as large investment cost. The payback times for the mixtures with the best economic performance are only slightly longer than for ammonia, as indicated in Table 4. 
Table 4: Performance indicators for selected fluids with promising economic performance from screening of case I

\begin{tabular}{lrrrrrrr}
\hline Medium & COP & \multicolumn{1}{c}{$\begin{array}{c}p_{\text {evap }} \\
\text { bar }\end{array}$} & $\begin{array}{c}p_{\text {cond }} \text { bar } \\
\text { Ammonia }\end{array}$ & $\begin{array}{c}\mathrm{TCI}_{\text {spec }} \\
€ / \mathrm{kW}\end{array}$ & $\begin{array}{c}\text { NPV } \\
1000 €\end{array}$ & $\begin{array}{c}\text { PBT } \\
\text { years }\end{array}$ & $\begin{array}{c}c_{\mathrm{h}} \\
€ / \mathrm{MWh}\end{array}$ \\
\hline Butane & 4.6 & 9.1 & 35.1 & 375 & 624 & 3.4 & 30.1 \\
R-1234ze(E) & 4.5 & 2.2 & 9.5 & 663 & 448 & 5.9 & 32.9 \\
$20 \%$ CO2 / 80 \% DME & 4.4 & 4.6 & 18.5 & 511 & 497 & 4.9 & 32.2 \\
$30 \%$ Propylene / 70 \% R-1234ze(Z) & 5.6 & 9.7 & 25.3 & 591 & 763 & 4.0 & 27.3 \\
$50 \%$ Propylene / 50 \% Butane & 6.2 & 5.7 & 14.6 & 740 & 781 & 4.5 & 26.7 \\
80 \% Propane / 20 \% Iso-Pentane & 5.6 & 6.0 & 16.4 & 623 & 736 & 4.2 & 27.8 \\
$50 \%$ DME / 50 \% Iso-Pentane & 5.6 & 7.4 & 18.9 & 647 & 728 & 4.3 & 27.9 \\
\hline
\end{tabular}

Case II: $T_{\text {Source }} 40^{\circ} \mathrm{C} \rightarrow 25^{\circ} \mathrm{C} ; T_{\text {sink }} \underline{50^{\circ} \mathrm{C} \rightarrow 75^{\circ} \mathrm{C}}$

Figure 5 and Table 5 show the corresponding information for case II. The obtained COPs for the pure fluids are in the same range as for case I. The performances for mixtures reach COPs above 6.0 for case II, while they were above 6.5 for case I. The specific cost of heat for the pure fluids are $31 € / \mathrm{MWh}$ or larger, while the best mixtures reach values around $28.5 € / \mathrm{MWh}$. The mixture of $60 \%$ propylene and $40 \%$ butane shows the best economic performance and a COP of 5.8, corresponding to an increase in thermodynamic performance of $30 \%$ and a reduction of $8 \%$ in the specific cost of heat compared to ammonia.

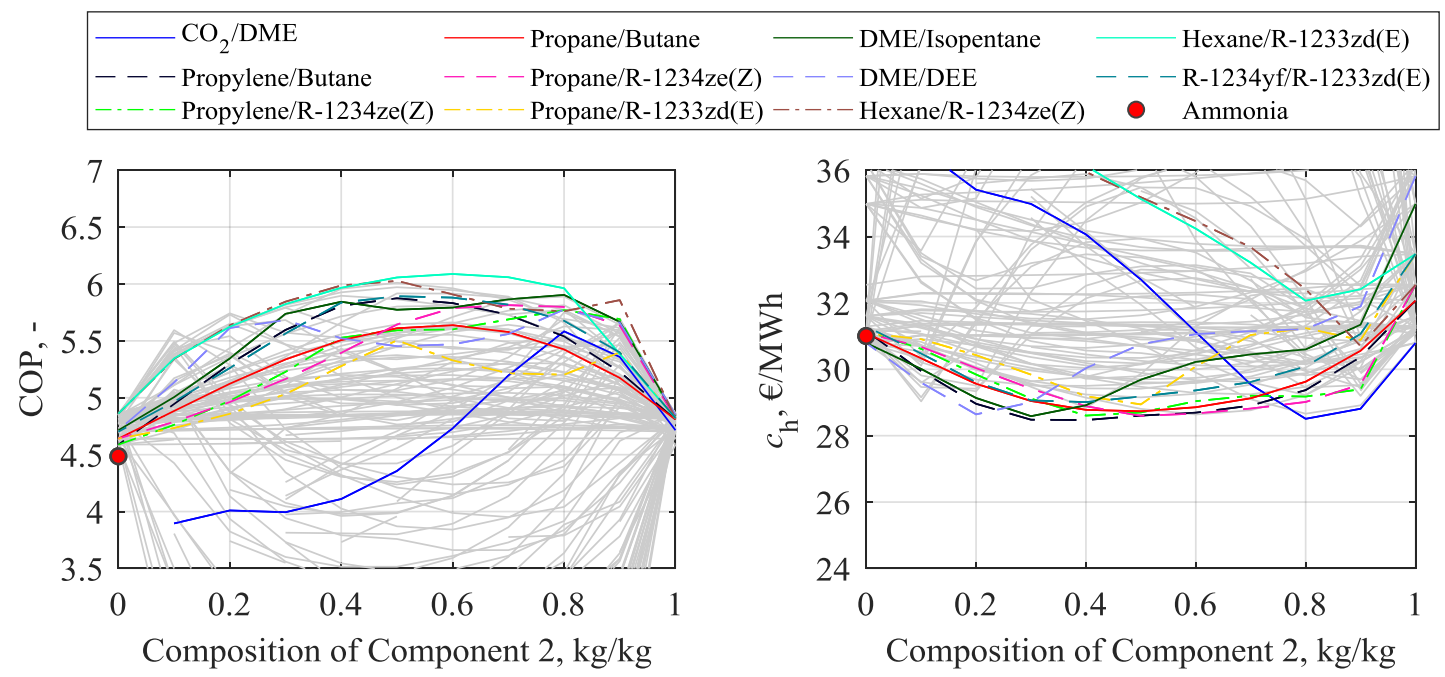

Figure 5: COP (left) and the specific cost of heat (right) over the composition of component 2 with most promising fluid indicated by colors for case II

Table 5: Performance indicators for selected fluids with promising economic performance from screening of case II

\begin{tabular}{lrrrrrrr}
\hline Medium & COP & \multicolumn{1}{c}{$\begin{array}{c}p_{\text {evap }} \\
\text { bar }\end{array}$} & $\begin{array}{c}p_{\text {cond }} \\
\text { bar }\end{array}$ & $\begin{array}{c}\mathrm{TCI}_{\text {spec }} \\
€ / \mathrm{kW}\end{array}$ & $\begin{array}{c}\mathrm{NPV} \\
1000 €\end{array}$ & $\begin{array}{c}\text { PBT } \\
\text { years }\end{array}$ & $\begin{array}{c}c_{\mathrm{h}} \\
€ / \mathrm{MWh}\end{array}$ \\
\hline Ammonia & 4.5 & 9.1 & 34.2 & 423 & 567 & 4.0 & 31.0 \\
Butane & 4.8 & 2.2 & 8.9 & 710 & 493 & 5.9 & 32.1 \\
R-1234ze(E) & 4.7 & 4.6 & 17.2 & 585 & 547 & 5.0 & 31.2 \\
$20 \%$ CO2 / 80 \% DME & 5.6 & 9.4 & 24.7 & 700 & 690 & 4.7 & 28.5 \\
$40 \%$ Propylene / 60 \% R-1234ze(Z) & 5.6 & 6.2 & 16.7 & 759 & 658 & 5.1 & 29.0 \\
$60 \%$ Propylene / 40 \% Butane & 5.8 & 7.2 & 18.2 & 779 & 687 & 5.0 & 28.5 \\
$60 \%$ Propane / 40 \% R-1234ze(Z) & 5.4 & 7.1 & 19.6 & 662 & 672 & 4.7 & 28.9 \\
$50 \%$ Propane / 50 \% Butane & 5.6 & 5.5 & 15.3 & 732 & 676 & 4.9 & 28.7 \\
\hline
\end{tabular}


Figure 6 shows the specific total capital investment cost $\mathrm{TCI}_{\text {spec }}$ and the COP for all fluids in a scatter plot. The levelized specific cost of heat $c_{\mathrm{h}}$ is indicated as a measure of the economic performance. The COPs of the pure fluids are all in a limited range around 4.5 for case I, while they approach COPs of 5 for case II using the IHX cycle. Lower cost of heat is mainly achieved by a reduced specific investment cost, which varies between $400 € / \mathrm{kW}$ to $1,200 € / \mathrm{kW}$. The mixtures vary more and reach COPs of up to 6.6 for case I and around 6.1 for case II. The diagrams show however that the best economic performance is not obtained for the highest COPs but rather by a combination for both the COP and the investment cost. The Pareto front of the mixtures visualizes that the COPs of the mixtures increase enough to compensate the increasing investment with respect to the economic boundary conditions.

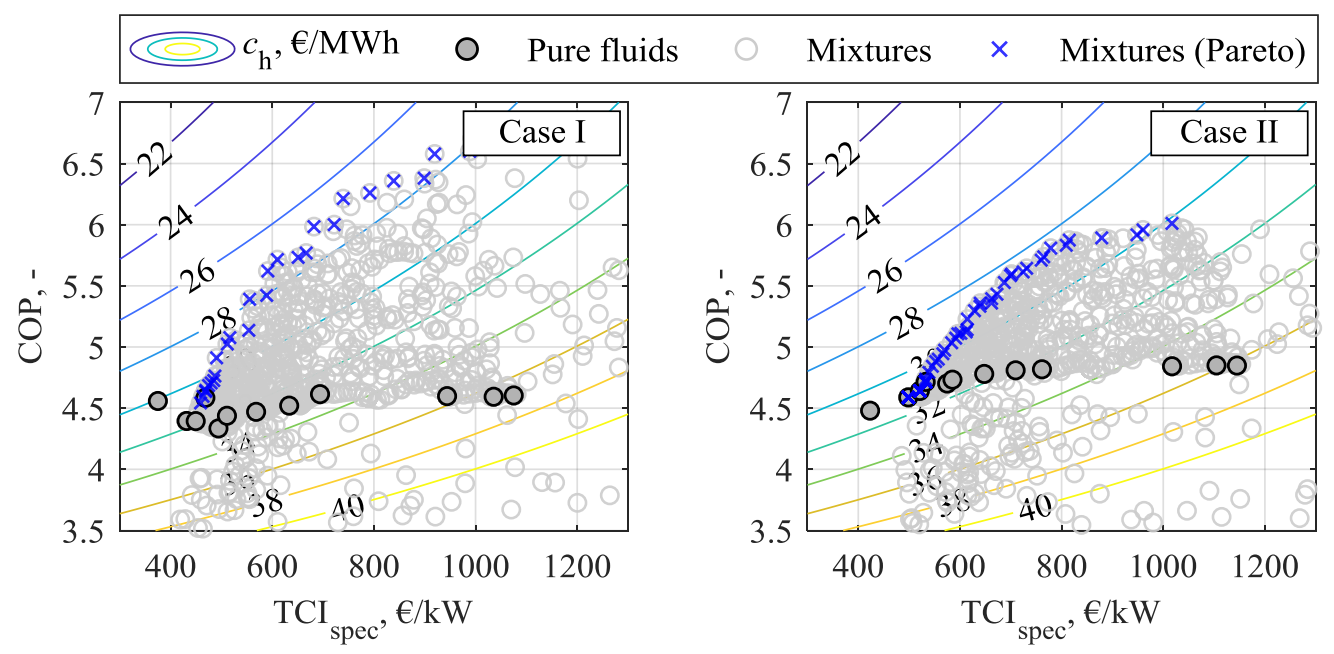

Figure 6: Scatter plot for all fluids showing the COP and the specific investment cost $\mathrm{TCI}_{\text {spec }}$ for both cases indicating the pure fluids and the mixtures in the Pareto front with respect to $c_{\mathrm{h}}$

\subsection{Analysis of suitable assumptions for heat exchanger dimensioning}

In order to analyze the consistency of the discussed assumptions for the dimensioning of the heat exchangers for the purpose of comparing pure fluids and mixtures, the introduced approaches were compared on a theoretical basis and subsequently evaluated for the two case studies.

\subsubsection{Theoretical Analysis}

An analysis of the heat exchanger area and the relation to the performance revealed, that an increasing heat exchanger area resulted for the case of relatively large temperature differences in a reduction of the mean temperature differences $\bar{T}_{\text {Cond }}-\bar{T}_{\text {Evap }}$ and thereby in an improving performance. The temperature difference between the average condensation and evaporation temperature $\bar{T}_{\text {Cond }}-\bar{T}_{\text {Evap }}$ was however limited by minimum pinch point temperature differences that were approaching $0 \mathrm{~K}$, which corresponds to infinite heat exchanger area. For the case of an ideal pure fluid, the minimum temperature difference between average condensation temperature and evaporation temperature was limited by $\left(\bar{T}_{\text {Cond }}-\bar{T}_{\text {Evap }}\right) \geq$ $\left(T_{\text {Sink,out }}-T_{\text {Source,out }}\right)$. A mixture with an ideal temperature glide match with the source and the sink can however reach an improved performance corresponding to a reduced difference between average condensation and evaporation temperature of $\left(\bar{T}_{\text {Cond }}-\bar{T}_{\text {Evap }}\right) \geq\left(\bar{T}_{\text {Sink }}-\bar{T}_{\text {Source }}\right)$. 

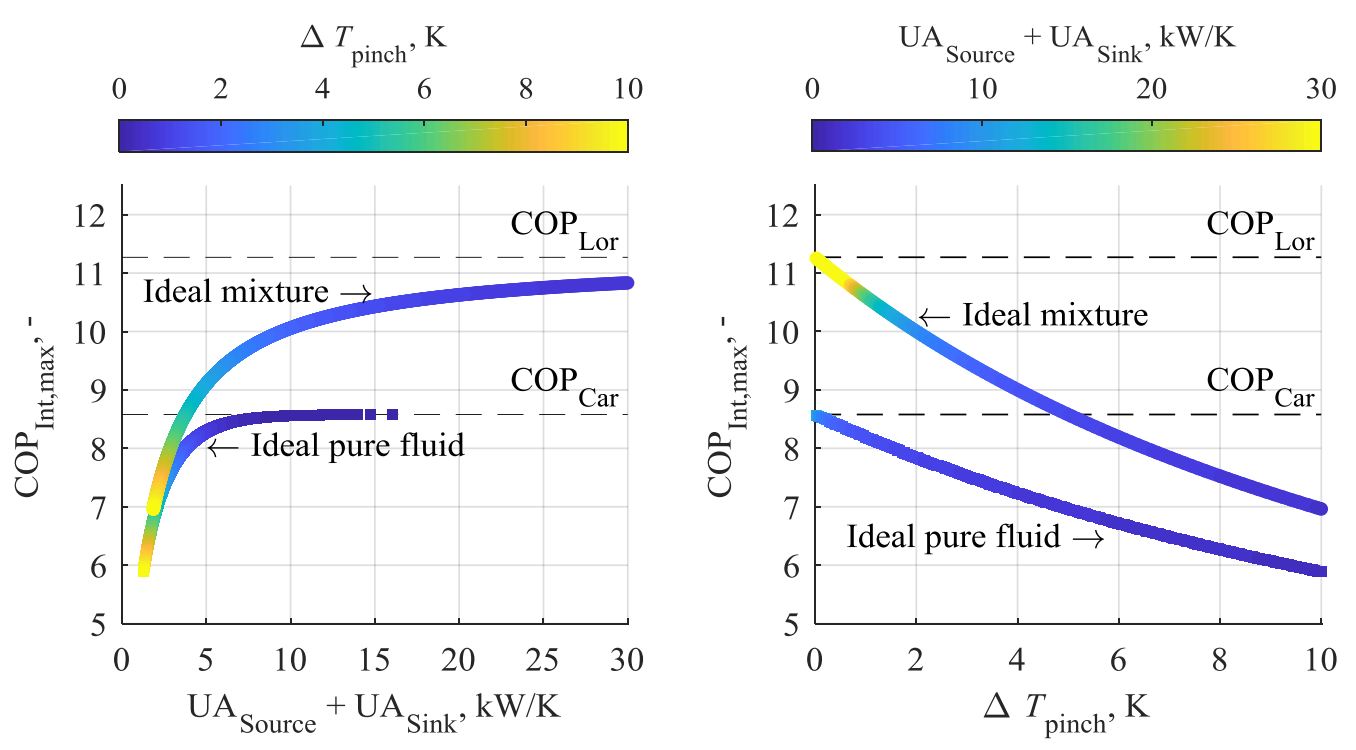

Figure 7: Performance and the sum of the UA-values of source and sink of an ideal pure fluid and an ideal mixture for a variation of $\Delta T_{\text {pinch }}$ for an exemplifying case: Source $40{ }^{\circ} \mathrm{C} \rightarrow 30^{\circ} \mathrm{C}$, Sink $60{ }^{\circ} \mathrm{C} \rightarrow 70^{\circ} \mathrm{C}$ and $1 \mathrm{MW}$ supplied heat

Figure 7 shows the COP for both an ideal pure and mixed fluid and the sum of the UA-value for heat source and sink for a variation of the pinch point temperature difference for an exemplifying case. The diagram shows the relation in two diagrams, with one focusing on the UA-values (left) and the other on the pinch point temperature differences (right). The ideal pure fluid converges to $\mathrm{COP}_{\mathrm{Car}}$ for a decreasing temperature difference and an increasing area, respectively, while the ideal mixture converges towards $\mathrm{COP}_{\text {Lor. }} \mathrm{A}$ comparison of the performance based on a complete heat exchanger area corresponding to a UA-value of $5 \mathrm{~kW} / \mathrm{K}$ appears to be a solution at which the ideal pure fluid shows a performance that is close to its maximum. The ideal mixture instead shows a significant potential performance improvement for the choice of a larger heat exchanger investment. The tradeoff between the heat exchanger area and the performance is fluid specific, which means that no heat exchanger size distribution can be found that is economically optimal for all fluids. A mixture for which an investment in additional heat exchanger area yields an increased performance might economically compensate the investment by an improved performance, while this is not the case for a pure fluid, for which an additional heat exchanger area results in only a limited performance increase. Any choice of a specific parameter defining the reference size for the comparisons therefore may lead to omission of promising solutions and might inherently be more or less optimal for one or the other fluid.

Following this argumentation, it becomes apparent that a zeotropic mixture with a good temperature glide match with the heat source and sink implies the potential to operate at a higher performance, while the maximum obtainable performance of pure fluids is limited to a lower value, even under consideration of infinite heat exchanger areas. It becomes accordingly undisputed, that any approach for comparison of pure fluids and mixtures, which is based on a specific heat exchanger area or a fixed thermodynamic average temperature difference, limits the possibilities for exploiting the potential performance improvement that is obtainable by using mixtures.

Figure 7 indicates that the tradeoff among the heat exchanger area and the possible performance increase is more precisely appraisable by using a fixed pinch point temperature difference for the heat exchanger design. Assuming e.g. a pinch point temperature difference of $2 \mathrm{~K}$ yields a performance, which is for both the pure and the mixed fluid at approximately $90 \%$ of the respectively maximum achievable performance. We do therefore suggest designing the heat exchanger area for each fluid by assuming a minimum pinch point 
temperature difference for all fluids. Such a definition requires a certain engineering experience but implies the possibility to provide a comparison in which each fluid operates at its optimal heat exchanger area.

\subsubsection{Analysis based on case studies}

In total three approaches were evaluated for both cases for the fluids with the most promising economic performance. Approach a) defined the heat exchangers by a fixed pinch point temperature difference of $3 \mathrm{~K}$. Approach $b$ ) defined the overall heat exchanger investment to the value that was obtained for ammonia by fixing the pinch point temperature difference, while the distribution of the area to the source and sink heat exchanger was optimized. Both approaches were compared to option c) in which the heat exchanger areas were optimized with respect to a maximum NPV considering constraints for the minimum temperature differences of $1 \mathrm{~K}$.

Figure 8 summarizes the results of the comparison for case I (left) and case II (right). It shows that the three approaches yield comparable results in both COP and NPV for the pure fluids, while the restriction in heat exchanger size in b) yields a limited performance of the mixtures. Under the assumption of an equal heat exchanger investment, the mixtures are not able to exploit their full thermodynamic and economic potential and perform at performances similar to pure fluids. If the heat exchangers are however designed for each fluid by defining the minimum pinch point difference as in a), both the thermodynamic and economic performance increase to values that are obtained under optimized conditions.

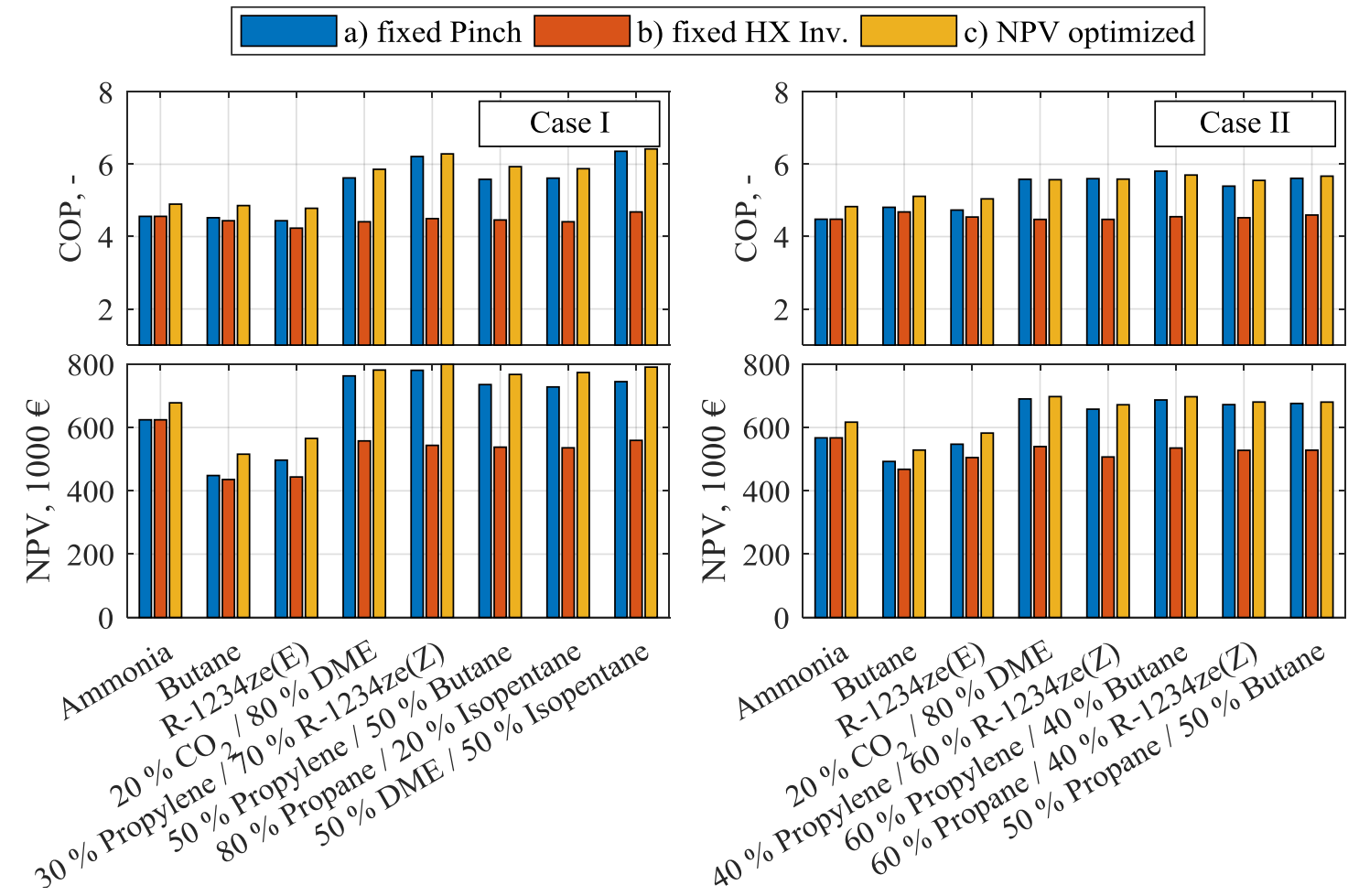

Figure 8: COP (top) and NPV (bottom) for selected fluids of case I and case II for 3 options: a) fixed pinch point temperature differences, $\mathrm{b}$ ) fixed overall heat transfer investment to the value for ammonia, c) heat transfer area optimized with respect to the NPV assuming a plant lifetime of $n=20$ years

In order to study the influence of the plant lifetime, the same analysis was repeated for the same cases assuming a lower plant lifetime of $n=10$ years. The results are summarized in Figure 9. The COP of all fluids for approach a) and b) are the same as in Figure 8 and accordingly independent of the plant lifetime. The COP for approach c) are however slightly lower, since the assumed shorter lifetime caused a lower optimal investment and thereby a decreased thermodynamic performance. The NPV were generally lower compared 
to a lifetime of 20 years while the relative differences between approach a) and c) compared to b) were similar. The trends did not differ between case I and case II, irrespective of the assumed lifetime.

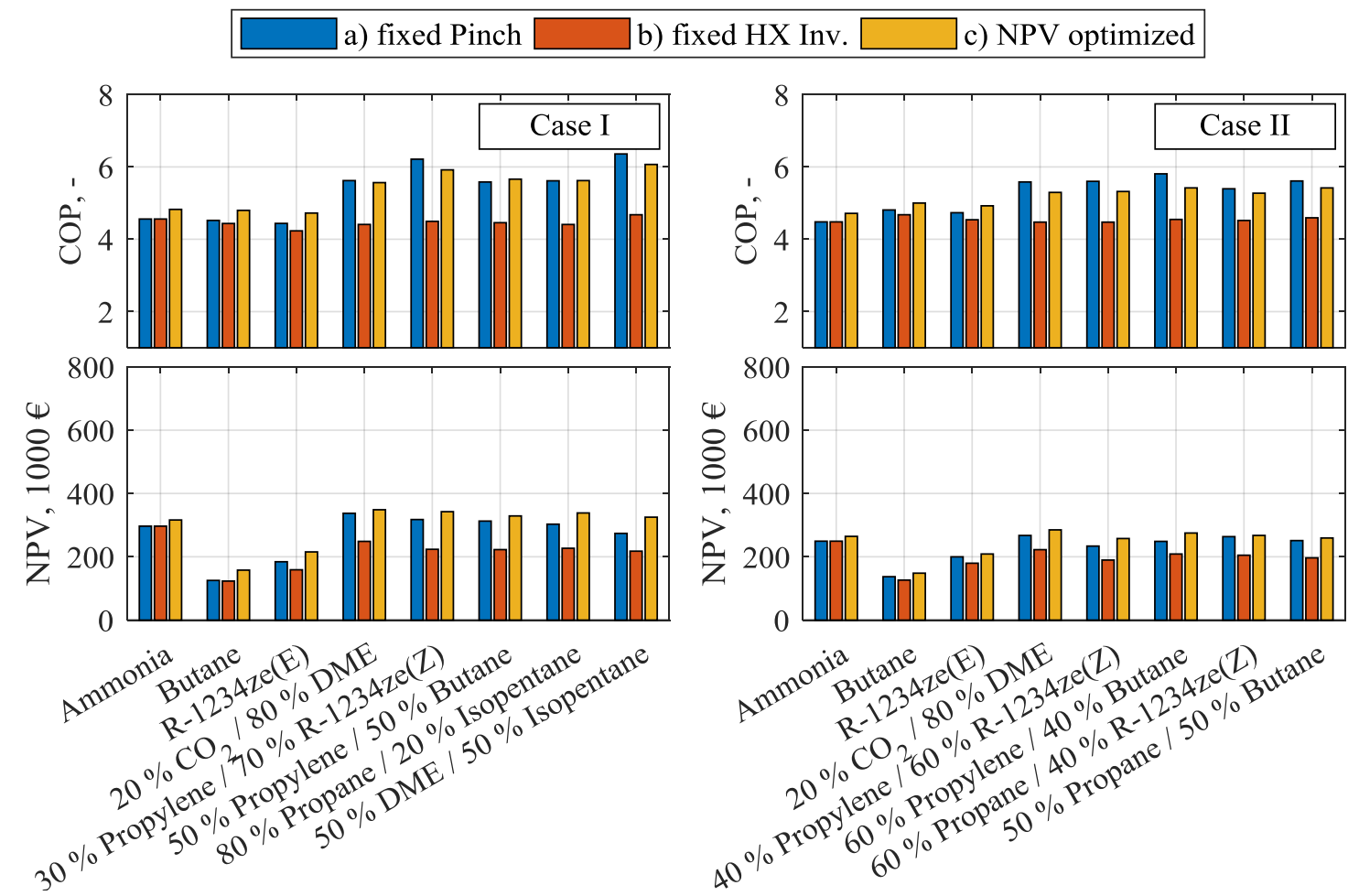

Figure 9: COP (top) and NPV (bottom) for selected fluids of case I and case II for 3 options: a) fixed pinch point temperature differences, $b$ ) fixed overall heat transfer investment to the value for ammonia, c) heat transfer area optimized with respect to the NPV assuming a plant lifetime of $n=10$ years

The findings from Figure 8 and Figure 9 are consistent with the conclusions derived from Figure 7. The definition of the minimum pinch point temperature differences enables the exploitation of the thermodynamic potential, which resulted in an enhanced exploitation of the economic potential, too. The results indicated furthermore that the increased investment for mixtures can be compensated within lifetimes as low as 10 years, for the cases in which the additional investment enabled an improved thermodynamic performance.

\section{Discussion}

The work suggested and demonstrated a method that provides a ranking of the different working fluids with respect to their thermodynamic and economic performance by use of acknowledged design approaches. The method is based on experiences from different screenings and summarized in the appendix. The exact thermodynamic and economic performance is however dependent on the final design of components, as e.g. the different fluids show different reachable isentropic efficiencies, as described by Meroni et al. (2018), or might differently compensate pressure drops induced by the heat exchanger equipment, as described by Mancini et al. (2018). Appropriate analyses for addressing these aspects are numerically demanding and would exceed both the acceptable effort as well as the required accuracy of a preliminary screening analysis. After having conducted a screening analysis as presented by this paper, a more detailed analysis may be conducted to evaluate the different solutions in more detail. The more detailed analysis might furthermore comprise an analysis of the off-design behavior, as demonstrated by Zühlsdorf et al. (2018b), and a sensitivity analysis of the most influential assumptions, such as the thermodynamic or economic boundary conditions.

Different approaches for the sizing of the equipment were introduced and compared. Different studies, e.g. (Högberg and Berntsson, 1994; McLinden et al., 2017; McLinden and Radermacher, 1987), suggested 
fixing the overall heat exchanger area in relation to the transferred heat as a basis for rational comparisons of working fluids. This approach was compared to designing the heat exchangers by the definition of a minimum pinch point temperature difference, as applied in e.g. (Bamigbetan et al., 2016; Zühlsdorf et al., 2018b, 2018c). The presented analysis has shown that any limitation of the heat exchanger area constrains the possibilities for the zeotropic mixtures to exploit their full thermodynamic and economic potential for the described application and suggested that the definition of a fixed pinch point temperature difference appears to be a better assumption with respect to the defined performance indicators. It is however crucial to highlight, that this conclusion is based on the chosen application as well as on the chosen performance indicators. It is expected that fixing the pinch point temperature differences is favorable for the identification of high-performance fluids in which the application is being evaluated with a focus on the performance. This means that the application offers the potential to increase the thermodynamic performance by using mixtures and that the economic boundary conditions enable the improved performance to compensate the increased investment. In cases in which low investment is of higher importance or in which no performance increase can be obtained by temperature glide matching, e.g. when heat sink and source have constant temperatures, the approach of fixing the heat exchanger area in relation to the supplied heat or cold appears to be suitable.

The rationality of underlying assumptions is thereby dependent on the purpose of the screening. Our suggestions aim to identify cycles with a high thermodynamic performance rather than cycles with a limited investment and therefore follow a design approach with a focus on the performance, rather than on the investment. Other authors have however suggested various other approaches which might be reasonable for screenings with another purpose.

\section{Conclusion}

The paper focused on the evaluation and comparison of pure and mixed working fluids for applications, in which a performance increase is obtainable by using zeotropic mixtures. A procedure for evaluating and comparing the fluids was suggested. Different approaches for the heat exchanger design were compared and it was shown that fixing the pinch point temperature differences yielded the results that were closest to the values for an economically optimized solution. This means that an increased investment must be accepted in order to allow the mixtures exploiting their full thermodynamic and economic potential.

The screening method was demonstrated for two cases focusing on the utilization of excess heat from data centers and supply heat to district heating systems. The two analyzed cases differed by the heat source temperature glide. It was found for case I that a mixture of $30 \%$ propylene and $70 \% \mathrm{R}-1234 \mathrm{ze}(\mathrm{Z})$ is expected to improve the thermodynamic performance by $>35 \%$ and decrease the levelized specific cost of heat by $10 \%$ compared to ammonia. For case II, a mixture of $60 \%$ propylene and $40 \%$ butane was found to show the best economic performance with a cost reduction of $8 \%$ and an improvement of $30 \%$ in COP, compared to the best performing pure fluid.

Based on these findings, it was concluded that zeotropic mixtures imply the potential to significantly improve both the thermodynamic and economic performance of heat pumps in suitable applications, but require an appropriate cycle design. Suitable applications are applications in which there is a potential performance increase expected when using zeotropic mixtures and in which the economic boundary conditions remunerate solutions with a high thermodynamic performance. An appropriate design requires designing the components based on the specific refrigerants in order to fully exploit the potential benefits as demonstrated by the suggested screening procedure.

\section{Acknowledgements}

This research project is financially funded by The Danish Council for Strategic Research in Sustainable Energy and Environment, under the project title: "THERMCYC - Advanced thermodynamic cycles utilizing low-temperature heat sources" and by EUDP (Energy Technology Development and Demonstration) under the 
project title "Mixed refrigerant heat pumps/cooling systems (MIREHP)" with the grant number 64016-0045. The support is gratefully acknowledged. 
Nomenclature

Abbreviations:

GWP

Global warming potential

IHX

HFC

Hydrofluorocarbon

ODP

Internal heat exchanger

HFO

Hyrdofluoroolefin

Ozone depletion potential

\section{Latin Symbols:}

A

$c_{\mathrm{h}}$

COP

$\mathrm{COP}_{\mathrm{Car}}$

$\mathrm{COP}_{\text {Lor }}$

$\mathrm{COP}_{\text {Int,max }}$

$\mathrm{CF}_{\mathrm{el}}$

$\mathrm{CF}_{\text {Source }}$

$\mathrm{CF}_{\text {Supply }}$

CRF

$f_{\text {TCI }}$

$h_{\mathrm{i}}$

$i_{\text {eff }}$

$n$

NPV

$\mathrm{OH}$

PBT

PEC

$\dot{Q}_{\text {IHX }}$

$\dot{Q}_{\text {Loss.Comp }}$

$\dot{Q}_{\text {Sink }}$

$\dot{Q}_{\text {Source }}$

TCI Total capital investment cost, $€$

$\bar{T}_{\text {Cond }}$

$\bar{T}_{\text {Cond,pure }}$
Heat exchange area, $\mathrm{m}^{2}$

Levelized specific cost of heat, $€ / \mathrm{MWh}$

Coefficient of performance, -

Carnot COP, -

Lorenz COP, -

Maximum Lorenz COP of internal

cycle, -

Annual cash flow associated to electricity consumption, $€$ /year

Annual cash flow associated to heat consumption, $€ /$ year

Annual cash flow associated to

heat supply, $€$ /year

Capital recovery factor, $1 /$ year

Factor for estimation of TCI, -

Specific enthalpy at state point $i$,

$\mathrm{kJ} / \mathrm{kg}$

Effective interest rate, -

Life time of plant, years

Net present value, $€$

Annual operating hours, $\mathrm{h} / \mathrm{year}$

Payback time, years

Purchased equipment cost, $€$

Heat transferred in IHX, kW

Heat loss from compressor, $\mathrm{kW}$

Heat load transferred to sink, $\mathrm{kW}$

Heat load transferred from source, $\mathrm{kW}$

Thermodynamic average

temperature of condenser, ${ }^{\circ} \mathrm{C}$ or $\mathrm{K}$

Thermodynamic average

temperature of condenser for ideal

pure fluid, ${ }^{\circ} \mathrm{C}$ or $\mathrm{K}$
$\bar{T}_{\text {Cond,mix }}$

$\bar{T}_{\text {Evap }}$

$\bar{T}_{\text {Evap,pure }}$

$\bar{T}_{\text {Evap,mix }}$

$\bar{T}_{\text {Sink }}$

$T_{\text {Sink,in }}$

$T_{\text {Sink,out }}$

$\bar{T}_{\text {Source }}$

$T_{\text {Source,in }}$

$T_{\text {Source,out }}$

$U$

UA

$\mathrm{UA}_{\text {Sink }}$

$\mathrm{UA}_{\text {Source }}$

VHC

$v_{\mathrm{i}}$

$\dot{W}_{\text {Comp }}$

$\Delta T_{\text {in }}$
Thermodynamic average

temperature of condenser for ideal mixture, ${ }^{\circ} \mathrm{C}$ or $\mathrm{K}$

Thermodynamic average temperature of evaporator, ${ }^{\circ} \mathrm{C}$ or K

Thermodynamic average temperature of evaporator for ideal pure fluid, ${ }^{\circ} \mathrm{C}$ or $\mathrm{K}$

Thermodynamic average temperature of evaporator for ideal mixture, ${ }^{\circ} \mathrm{C}$ or $\mathrm{K}$

Thermodynamic average temperature of sink, ${ }^{\circ} \mathrm{C}$ or $\mathrm{K}$ Sink inlet temperature, ${ }^{\circ} \mathrm{C}$ or $\mathrm{K}$ Sink outlet temperature, ${ }^{\circ} \mathrm{C}$ or $\mathrm{K}$ Thermodynamic average temperature of source, ${ }^{\circ} \mathrm{C}$ or $\mathrm{K}$ Source inlet temperature, ${ }^{\circ} \mathrm{C}$ or $\mathrm{K}$ Source outlet temperature, ${ }^{\circ} \mathrm{C}$ or K

Heat transmission coefficient, $\mathrm{kW} /\left(\mathrm{m}^{2} \mathrm{~K}\right)$

Heat conductance, $\mathrm{kW} / \mathrm{K}$

Overall heat conductance of condenser, $\mathrm{kW} / \mathrm{K}$

Overall heat conductance of evaporator, $\mathrm{kW} / \mathrm{K}$

Volumetric heating capacity, $\mathrm{kJ} / \mathrm{m}^{3}$

Specific volume at state point $i$, $\mathrm{m}^{3} / \mathrm{kg}$

Compressor work, $\mathrm{kW}$

\section{Greek Symbols:}

$\varepsilon$

$\eta_{\text {Lor }}$

ergetic efficiency,

Lorenz efficiency, -
Temperature difference at heat exchanger inlet, $\mathrm{K}$ 
$\Delta T_{\text {out }}$

Temperature difference at heat exchanger outlet, $\mathrm{K}$

$\Delta T_{\text {Pinch }}$

$\Delta T_{\text {Pinch,Sink }}$
Pinch point temperature

difference, $\mathrm{K}$

Pinch point temperature

difference in condenser, $\mathrm{K}$
$\Delta T_{\text {Pinch,Source }}$

Pinch point temperature difference in evaporator, $\mathrm{K}$

$\Delta T_{\text {Sink }}$

$\Delta T_{\text {Source }}$
Sink temperature glide, $\mathrm{K}$

Source temperature glide, $\mathrm{K}$ 


\section{References}

Alefeld, G., 1987. Efficiency of compressor heat pumps and refrigerators derived from the second law of thermodynamics. International Journal of Refrigeration 10, 331-341. doi:10.1016/0140-7007(87)901198

ASHRAE, 2016. ANSI/ASHRAE Standard 34-2016 - Designation and Safety Classification of Refrigerants. American Society of Heating, Refrigerating and Air-Conditioning Engineers.

ASHRAE Technical Committee, 2016. ASHRAE TC 9.9 - Data Center Power Equipment Thermal Guidelines and Best $\quad$ Practices DWW Document]. URL https://tc0909.ashraetcs.org/documents/ASHRAE_TC0909_Power_White_Paper_22_June_2016_REVI SED.pdf (accessed 9.30.18).

Bamigbetan, O., Eikevik, T., Nekså, P., Bantle, M., 2016. Evaluation of natural working fluids for the development of high temperature heat pumps. 12th IIR Gustav Lorentzen Natural Working Fluids Conference, Edinburgh, Scotland, 2016 1-8. doi:10.18462/iir.gl.2016.1092

Bamigbetan, O., Eikevik, T.M., Nekså, P., Bantle, M., Schlemminger, C., 2018. Theoretical analysis of suitable fluids for high temperature heat pumps up to $125^{\circ} \mathrm{C}$ heat delivery. International Journal of Refrigeration 92, 185-195. doi:10.1016/j.jirefrig.2018.05.017

Bejan, A., Tsatsaronis, G., Moran, M., 1996. Thermal Design and Optimization, Thermal Design and Optimization. doi:10.1016/S0140-7007(97)87632-3

Bell, I.H., Lemmon, E.W., 2016. Automatic Fitting of Binary Interaction Parameters for Multi-fluid Helmholtz-Energy-Explicit Mixture Models. Journal of Chemical \& Engineering Data 61, 3752-3760. doi:10.1021/acs.jced.6b00257

Bell, I.H., Wronski, J., Quoilin, S., Lemort, V., 2014. Pure andPseudo-pure Fluid Thermophysical Property Evaluation and the Open-SourceThermophysical Property Library CoolProp. Industrial \& Engineering Chemistry Research 53, 2498-2508. doi:dx.doi.org/10.1021/ie4033999

Besbes, K., Zoughaib, A., Carlan, F. De, Peureux, J.-L., 2014. Exergy Based Methodology for Optimized Integration of Heat Pumps in Industrial Processes. International Refrigeration and Air Conditioning Conference.

Cignitti, S., 2018. Optimization-based design of waste heat recovery systems. Technical University of Denmark (DTU).

Crowl, D.A., Louvar, J.F., 2001. Chemical Process Safety: Fundamentals with Applications, 2nd ed. Prentice Hall.

Dai, B., Li, M., Ma, Y., Dang, C., Li, M., Tian, H., Ma, Y., 2014. Thermodynamic performance assessment of carbon dioxide blends with low-global warming potential (GWP) working fluids for a heat pump water heater. International Journal of Refrigeration 64, 942-952. doi:10.1016/j.ijrefrig.2014.11.009

Dansk Standard, 2016. DS/EN 378-1:2016 - Danish Standard Refrigerating systems and heat pumps - Safety and environmental requirements - Part 1: Basic requirements, definitions, classification and selection criteria. Copenhagen.

Domanski, P.A., McLinden, M.O., 1990. A simplified cycle simulation model for the performance rating of refrigerants and refrigerant mixtures. International Journal of Refrigeration 15, 81-88. doi:10.1016/01407007(92)90031-O

Domanski, P.A., Mulroy, W.J., Didion, D.A., 1994. Glide matching with binary and ternary zeotropic refrigerant mixtures Part 2. A computer simulation. International Journal of Refrigeration 17, 226-230. doi:10.1016/0140-7007(94)90037-X

Domanski, P.A., Steven Brown, J., Heo, J., Wojtusiak, J., McLinden, M.O., 2014. A thermodynamic analysis 
of refrigerants: Performance limits of the vapor compression cycle. International Journal of Refrigeration 38, 71-79. doi:10.1016/j.ijrefrig.2013.09.036

Energistyrelsen, 2017. Danish Energy Agency [WWW Document]. Samfundsøkonomiske Beregningsforudsætninger for Energipriser og emissioner. doi:ISBN: 978-87-93180-29-1

European Parliament, 2014. Regulation (EU) No 517/2014 of the European Parliament and of the Council of 16 April 2014 on fluorinated greenhouse gases and repealing Regulation (EC) No 842/2006. Official Journal of the European Union 2014, L150/195-230.

Frutiger, J., Andreasen, J., Liu, W., Spliethoff, H., Haglind, F., Abildskov, J., Sin, G., 2016. Working fluid selection for organic Rankine cycles - Impact of uncertainty of fluid properties. Energy 109, 987-997. doi:10.1016/j.energy.2016.05.010

Frutiger, J., Zühlsdorf, B., Elmegaard, B., Abildskov, J., Sin, G., 2018. Reverse engineering of working fluid selection for industrial heat pump based on Monte Carlo sampling and uncertainty analysis. Industrial \& Engineering Chemistry Research. doi:10.1021/acs.iecr.7b04607

Fukuda, S., Kondou, C., Takata, N., Koyama, S., 2014. Low GWP refrigerants R1234ze(E) and R1234ze(Z) for high temperature heat pumps. International Journal of Refrigeration 40, 161-173. doi:10.1016/j.ijrefrig.2013.10.014

Guideline for Life Cycle $\quad 2016$. doi:http://www.iifiir.org/userfiles/file/about_iir/working_parties/WP_LCCP/08/Booklet-LCCPGuideline-V1.2-JAN2016.pdf

Högberg, M., Berntsson, T., 1994. Non-azeotropic mixtures as working fluids in two-stage economizer-type heat pumps. International Journal of Refrigeration 17, 417-429. doi:10.1016/0140-7007(94)90077-9

Jensen, J.K., Ommen, T., Markussen, W.B., Reinholdt, L., Elmegaard, B., 2015. Technical and economic working domains of industrial heat pumps: Part 2 - Ammonia-water hybrid absorption-compression heat pumps. International Journal of Refrigeration 55, 183-200. doi:10.1016/j.ijrefrig.2015.02.011

Jensen, J.K., Ommen, T., Reinholdt, L., Markussen, W.B., Elmegaard, B., 2018. Heat pump COP, part 2 : Generalized COP estimation of heat pump processes, in: Proceedings of 13th IIR Gustav Lorentzen Conference on Natural Refrigerants. pp. 1-8. doi:10.18462/iir.gl.2018.1386

Kim, J.H., Cho, J.M., Kim, M.S., 2008. Cooling performance of several CO2/propane mixtures and glide matching with secondary heat transfer fluid. International Journal of Refrigeration 31, 800-806. doi:10.1016/j.ijrefrig.2007.11.009

Lee, H., Troch, S., Hwang, Y., Radermacher, R., 2016. LCCP evaluation on various vapor compression cycle options and low GWP refrigerants. International Journal of Refrigeration 70, 128-137. doi:10.1016/j.ijrefrig.2016.07.003

Lemmon, E.W., Huber, M.L., McLinden, M.O., 2013. NIST Standard Reference Database 23: Reference Fluid Thermodynamic and Transport Properties-REFPROP, Version 9.1.

Lemmon, E.W., McLinden, M.O., 2001. Method for estimating mixture equation of state parameters. Thermophysical Properties and Transfer Processes of New Refrigerants Conference.

Lorenz, H., 1894. Beiträge zur Beurteilung von Kühlmaschinen. Zeitschrift des VDI 38, 62-68.

Mancini, R., Zühlsdorf, B., Kjær Jensen, J., Brix Markussen, W., Elmegaard, B., 2018. Deriving guidelines for the design of plate evaporators in heat pumps using zeotropic mixtures. Energy 156, 492-508. doi:10.1016/j.energy.2018.05.026

McLinden, M.O., Brown, J.S., Brignoli, R., Kazakov, A.F., Domanski, P.A., 2017. Limited options for lowglobal-warming-potential refrigerants. Nature Communications 8, 1-9. doi:10.1038/ncomms 14476

McLinden, M.O., Kazakov, A.F., Steven Brown, J., Domanski, P.A., 2014. A thermodynamic analysis of refrigerants: Possibilities and tradeoffs for Low-GWP refrigerants. International Journal of Refrigeration 
38, 80-92. doi:10.1016/j.jirefrig.2013.09.032

McLinden, M.O., Radermacher, R., 1987. Methods for comparing the performance of pure and mixed refrigerants in the vapour compression cycle. International Journal of Refrigeration 10, 318-325. doi:10.1016/0140-7007(87)90117-4

Meroni, A., Zühlsdorf, B., Elmegaard, B., Haglind, F., 2018. Design of centrifugal compressors for heat pump systems. Applied Energy 232, 139-156. doi:https://doi.org/10.1016/j.apenergy.2018.09.210

Mondejar, M.E., Haglind, F., 2018. Binary interaction parameters for the study of hydrofluoroolefins blends using cubic equations of state. Proceeding of the 1st IIR International Conference on the Application of HFO Refrigerant Paper ID: 1119. doi:10.18462/iir.hfo.2018. 1119

Mulroy, W.J., Domanski, P.A., Didion, D.A., 1994. Glide matching with binary and ternary zeotropic refrigerant mixtures Part 1. An experimental study. International Journal of Refrigeration 17, 220-225. doi:10.1016/0140-7007(94)90037-X

Myhre, G., Shindell, D., Bréon, F.-M., Collins, W., Fuglestvedt, J., Huang, J., Koch, D., Lamarque, J.-F., Lee, D., Mendoza, B., Nakajima, T., Robock, A., Stephens, G., Takemura, T., Zhang, H., 2013. Anthropogenic and Natural Radiative Forcing, Climate Change 2013: The Physical Science Basis. Contribution of Working Group I to the Fifth Assessment Report of the Intergovernmental Panel on Climate Change. doi:10.1017/ CBO9781107415324.018

Nielsen, S., Christensen, S.W., Thorsen, R.S., Elmegaard, B., 2018. Comparison of Heat Pump Design and Performance for Modern Refrigerants, in: Proceedings of 13th IIR Gustav Lorentzen Conference on Natural Refrigerants. doi:10.18462/iir.gl.2018.1149

Ommen, T., Jensen, J.K., Markussen, W.B., Reinholdt, L., Elmegaard, B., 2015. Technical and economic working domains of industrial heat pumps: Part 1 - single stage vapour compression heat pumps. International Journal of Refrigeration 55, 168-182. doi:10.1016/j.ijrefrig.2015.02.012

Radermacher, R., Hwang, Y., 2005. Vapor Compression Heat Pumps with Refrigerant Mixtures. CRC Press. The MathWorks Inc., 2018. MATLAB R2018a.

Tobaly, P., Terrier, M., Bouteiller, P., 2018. CO2 + Propane mixture as working fluid for refrigeration in hot climates. Experimental results of energy efficiency tests, in: 13th IIR Gustav Lorentzen Conference. Valencia. doi:10.18462/iir.gl.2018.1276

United Nations Environmental Programme, 2016. Report of the Twenty-Eighth Meeting of the Parties to the Montreal Protocol on Substances that Deplete the Ozone Layer. Kigali, Rwanda. doi:10.1002/9780470670590.wbeog931

Van de Bor, D.M., Infante Ferreira, C.A., 2013. Quick selection of industrial heat pump types including the impact of thermodynamic losses. Energy 53, 312-322. doi:10.1016/j.energy.2013.02.065

Velders, G.J.M., Fahey, D.W., Daniel, J.S., Andersen, S.O., McFarland, M., 2015. Future atmospheric abundances and climate forcings from scenarios of global and regional hydrofluorocarbon (HFC) emissions. Atmospheric Environment 123, 200-209. doi:10.1016/j.atmosenv.2015.10.071

Velders, G.J.M., Fahey, D.W., Daniel, J.S., McFarland, M., Andersen, S.O., 2009. The large contribution of projected HFC emissions to future climate forcing. Proceedings of the National Academy of Sciences 106, 10949-10954. doi:10.1073/pnas.0902817106

Venzik, V., Roskosch, D., Atakan, B., 2017. Propene/isobutane mixtures in heat pumps: An experimental investigation. International Journal of Refrigeration 76, 84-96. doi:10.1016/j.ijrefrig.2017.01.027

Vonsild, A., 2017. Ventilated Enclosures for Flammable Refrigerants. Heat Pumping Technologies Magazine $35,54-58$.

Zoughaib, A., 2017. Exergy-based Methodology for Cycle Architecture and Working Fluid Selection: Application to Heat Pumps, in: From Pinch Methodology to Pinch-Energy Integration of Flexible 
Systems. Elsevier, pp. 91-111.

Zühlsdorf, B., Bühler, F., Mancini, R., Cignitti, S., Elmegaard, B., 2017. High Temperature Heat Pump Integration using Zeotropic Working Fluids for Spray Drying Facilities, in: 12th IEA Heat Pump Conference. Rotterdam, pp. 1-11.

Zühlsdorf, B., Jensen, J.K., Cignitti, S., Madsen, C., Elmegaard, B., 2018a. Analysis of temperature glide matching of heat pumps with zeotropic working fluid mixtures for different temperature glides. Energy 153, 650-660. doi:https://doi.org/10.1016/j.energy.2018.04.048

Zühlsdorf, B., Jensen, J.K., Elmegaard, B., 2018b. Numerical models for the design and analysis of heat pumps with zeotropic mixtures, Rev01, https://figshare.com/s/575b3a3760275aee119e. doi:https://doi.org/10.11583/DTU.6825443

Zühlsdorf, B., Meesenburg, W., Ommen, T.S., Thorsen, J.E., Markussen, W.B., Elmegaard, B., 2018c. Improving the performance of booster heat pumps using zeotropic mixtures. Energy 154, 390-402. doi:https://doi.org/10.1016/j.energy.2018.04.137

Zühlsdorf, B., Riis Christiansen, A., Müller Holm, F., Funder-Kristensen, T., Elmegaard, B., 2018d. Analysis of possibilities to utilize excess heat of supermarkets as heat source for district heating. Energy Procedia - 16th International Symposium on District Heating and Cooling DHC2018 149, 276-285. doi:10.1016/J.EGYPRO.2018.08.192 


\section{Appendix A: Screening method}

The above descriptions showed the application of the procedure to identify promising working fluid mixtures to different case studies. Based on the findings from the presented studies and the experiences in previous works, the method can be summarized as follows:

1. Definition of the boundary conditions

The screening requires that the thermodynamic boundary conditions are defined. This could be the inlet and outlet temperatures of both sink and source and the supplied heat load or an equivalent set of variables.

2. Definition of a list of potentially feasible pure fluids

The pure fluids considered in the screening of mixtures should conform to the following aspects:

- Cover a wide range of typical influential parameters, such as the critical properties $T_{\mathrm{c}}$ and $p_{\mathrm{c}}$

$\circ$ Being miscible with as many as possible of the other fluids over wide ranges of pressure and temperature

- Current and future legislation on environmental impact on a local and international level

- Unwanted fluid characteristics, such as flammability, may be accepted at this stage

3. Screening of working fluids

- Selection of a cycle depending on the application

- Definition of the assumptions for the cycle evaluation: minimum pinch point temperature differences, isentropic efficiencies, required superheating

- If applicable, definition of approaches for sizing the equipment: Estimation of the heat exchanger area

- If applicable, implementation of functions for the estimation of the equipment cost and definition of economic boundary conditions

- Simulation of all considered fluid combinations at different compositions and documentation of the most important results

\section{Screening evaluation (Post-screening)}

The screening provides a list of fluids, which can be ranked by the introduced thermodynamic and economic performance indicators. Additional secondary aspects may be considered in the selection of the most promising fluids. Examples of more detailed screening evaluations are presented in (Mancini et al., 2018; Zühlsdorf et al., 2017, 2018c, 2018a, 2018d). The selection of the working fluids should comprise a sufficiently large number of candidates and consider:

- Thermodynamic performance criteria, such as the COP or suitable second law efficiencies, such as the exergetic efficiency $\varepsilon$ or the Lorenz efficiency $\eta_{\text {lor }}$.

- Economic performance indicators, such as the NPV or specific cost of heat $c_{\mathrm{h}}$, under consideration of the uncertainties in the assumptions

- The miscibility of the chosen mixture over a suitable range of pressure and temperature

- Flammability

- Sensitivity with respect to change in composition

- Uncertainties in the medium property calculations, especially for mixtures with estimated interaction parameters

- Detailed design and optimization of the heat exchanger equipment, incl. calculation of the pressure drop and the heat transfer coefficients 